\title{
Zur Altersfrage der mitteleuropäischen Terrae calcis
}

\author{
Von Libuše Smolíková \& Vojen Ložek \\ Mit 10 Abbildungen und 2 Tabellen im Text
}

\begin{abstract}
Zus ammenf assung: Vom Standpunkte der Quartärstratigraphie können die Terrae calcis-Böden wichtige Leithorizonte bieten, da ihre Entstehung auf warmzeitliche Klimabedingungen zurückgeht. Zunächst muß allerdings das Alter von einzelnen Terrae calcis-Typen und -Varietäten möglichst genau bestimmt werden.

Beste Anhaltspunkte für die Altersbestimmung von Terrae calcis bieten die Ausgangsgesteine bekannten Alters und das Verhältnis zur Erosion. Als Hilfskriterien können die fossilführenden Terrae calcis-Sedimente in Karsthohlräumen und das gegenseitige Verhältnis von einzelnen Terrae calcis-Typen in den Aufschlüssen angeführt werden. Die besten Ergebnisse wurden bisher auf Grund von Untersuchungen der Terrae calcis aus Travertinen und Kalkbreccien gewonnen, die altersmäßig in verschiedene Phasen des Jungtertiärs und Quartärs gehören.

Aus vergleichenden Studien im Karpatenraum geht eindeutig hervor, daß die jüngsten allitischen Terra rossa-Bildungen nur auf pliozänen Travertinen zu finden sind. Auf den Travertinen der pleistozänen Warmzeiten, abgesehen von den letztinterglazialen, ist üblicherweise die Terra fusca ausgebildet. Nur ausnahmsweise wurde flachgründige Terra fusca auch auf den letztinterglazialen (Eem-) Travertinen nachgewiesen, während die ho'ozänen Quellkalke lediglich Rendsinen tragen. Aus den angeführten Anhaltspunkten ergibt sich somit, daß die jüngsten allitischen Terra-rossaBildungen endtertiär bzw. höchstens ältestpleistozän sind. Die Terra fusca ist eine bezeichnende Bildung der pleistozänen Interglaziale, während im Postglazial nur eine sehr beschränkte, lokale Entstehung dieses Bodens anzunehmen ist. Aus einigen Befunden in den Karsthohlräumen kann geschlossen werden, daß siallitische Terra rossa auch in den ältestpleistozänen Warmzeiten gebildet wurde.

Wenn diese Gesetzmäßigkeiten noch an mehreren Fundstellen in verschiedenen Landschaften bestätigt würden, könnten die einzelnen Terrae calcis-Typen gute Alterskriterien in solchen Gebieten bieten, wo andere Anhaltspunkte nicht zur Verfügung stehen.
\end{abstract}

A bstract. From the standpoint of the Quaternary stratigraphy, soils of the terrae calcis group can represent important pedostratigraphical horizons, provided that the geological age of the different types can be determined precisely. The conditions of their development suggest that they are typical products of a warm climate.

The precise age determination of terrae calcis is most safely based on the age determination of the parent material and on their relation to erosion. As auxiliary criteria can serve fossiliferous fills of karst cavities built of terrae calcis sediments, and mutual relationship of individual types of these soils in the profiles. Best results were hitherto provided by investigating soils of the terrae calcis group which were developed on travertines and calcareous breccias dating from various periods of Late Tertiary and Quaternary.

Comparative studies in the Carpathian area have shown that the latest allitic terra rossa rests on travertines of Pliocene age. On travertines dating from Pleistocene interglacial periods, except for the Last Interglacial (Eemian), terra fusca is usually found. Exceptionally, thin layers of terra fusca have been observed also on travertines of Last Interglacial age, but never upon travertines of the Holocene age.

From the above-said it is evident that the youngest allitic terra rossa dates from the end of the Tertiary, from the onset of the Pleistocene at the latest. Terra fusca soils are typical for Pleistocene interglacials, whereas in the Postglacial they developed only locally, on a limited scale. From some finds in karst cavities it can be inferred that siallitic terra rossa continued to form even in warm periods of the earliest Pleistocene.

If this regularity (in the mutual relationship between the types of terrae calcis and time of their origin) is corroborated at other localities, it will be possible to use the individual types as a basis for age determination in areas where other criteria are lacking.

\section{Einleitung}

Die Frage des geologischen Alters der Böden der Terrae calcis-Gruppe ist bisher unklar, wie man sich aus den Angaben im Schriftum überzeugen kann. In neueren pedologischen Arbeiten über diese Böden wird angeführt, daß im Falle von mitteleuropäischen Vorkommen meist Reliktböden vorliegen, die in der geologischen Vergangenheit gebildet 
wurden (W. L. Kubiena 1953). Besonders gilt dies für die Bildung der Terra rossa, während eine - allerdings recht beschränkte - Terra fusca-Entstehung auch unter heutigen Klimabedingungen nicht ausgeschlossen werden kann (J. WERNER 1958).

Eine genaue Altersbestimmung von verschiedenen Typen und Varietäten der Terrae caicis ist für die Quartärgeologie von Bedeutung, da diese Böden in manchen Fällen als pedostratigraphische Leithorizonte dienen könnten. In den bisherigen geologischen Arbeiten gibt es in dieser Hinsicht eine beträchtliche Unsicherheit, da die Ansichten verschiedener Autoren, vor allem bezüglich des Alters von Terra rossa, sehr verschieden sind. Die Entstehung von Terra rossa wird sowohl in das Jungtertiär (J. PeLíšEK 1937 u. a., E. MüCKenhausen 1958, H. Franz 1960 usw.), als auch in die pleistozänen Interglaziale gestellt (M. Kretzor 1956, V. Ložex \& Fr. Prošek 1957); in extremen Fällen werden die Interstadiale (J. DvoǩÁk 1957) oder sogar das Postglazial in Betracht gezogen (z. B. J. Petrbok 1932, z. 'T. auch E. Blanck 1930, E. Blanck, E. v. Oldershausen \& G. MaurMANN 1932). Im allgemeinen fehlt eine genaue Bestimmung der besprochenen Böden. Nach den meisten Beschreibungen kann nicht entschieden werden, ob autochthone bzw. parautochthone Bodenbildungen oder nur Bodensedimente vorliegen. Außerdem werden in einigen Schriften Böden mit der Bezeichnung "Terra rossa“ angeführt, die mit dem erwähnten Bodentypus nur die Rubefizierung (rötliche Färbung) gemeinsam haben (z. B. K. Ž EBERA 1954).

Erst in den letzten Jahren wurde versucht, die mitteleuropäischen Terrae calcis anhand des Alters der Ausgangsgesteine, z. B. der Travertine (V. LožEk \& Fr. ProšEK 1957), der Kalkbreccien (V. LožEK 1960) und Gletscherablagerungen aus Karbonatmaterial (in den Alpen, vgl. J. FINK 1958, H. Franz 1956) oder nach dem Verhältnis zu pleistozänen A.btragungsvorgängen (J. WeRNER 1958) zu datieren. Auch die kolorimetrische Farbenbestimmung von Quartärablagerungen verschiedenen Alters (H. Alimen 1955) und die Bodenbildungen aus verschiedenaltrigen Terrassenschottern (J. Marković-Marjanović 1960, W. PAAs 1962) sowie die Ausbildung genau datierbarer Ausfüllungen von Karsthohlräumen (M. KRETzor 1956) sind von Bedeutung. Abgesehen von den sehr wertvollen, systematischen Untersuchungen $H$. KLINGES $(1956,1958)$ im Mittelmeergebiet sind aber diese Angaben in verschiedenen Schriften verstreut und entbehren meistens einer genaueren Beschreibung und Bestimmung der besprochenen Böden. Unser Beitrag hat sich zum Ziel gesetzt, die Altersfrage der Terrae calcis im Gebiet der Tschechoslowakei kurz zu besprechen, unsere bisherigen Beobachtungen zusammenzufassen (vgl. L. SMoLíková 1961a) und einige Gesetzmäßigkeiten festzustellen, die nach unseren Voraussetzungen im gesamten Mitteleuropa gültig sind.

\section{Möglichkeiten der geologischen Altersbestimmung von Terrae calcis}

Im Falle der meisten Terrae calcis-Vorkommen, insbesondere der Terra rossa-Relikte auf paläozoischen oder mesozoischen Kalken, stößt die Altersbestimmung auf große Hindernisse, bzw. kann praktisch nicht durchgeführt werden. Wie bereits W. L. KubIENA (1953, S. 262) hingewiesen hat, ist auf Grund der Lagerung und des Gefüges solcher Böden ihre Alterseinstufung schwer zu erkennen. Eine stratigraphische Korrelation dieser Böden mit stratigraphisch bedeutenden Ablagerungen, d. h. zum Beispiel mit Gletscherablagerungen, Lößserien oder Flußterrassen, bietet mangels geeigneter Profile nur sehr beschränkte Möglichkeiten. In der Tschechoslowakei ist die Beziehung von Terra rossa, bzw. ihrer Sedimente, zu tertiären Ablagerungen seit langem bekannt. So wird ein Teil der Terra rossa-Böden auf den Triaskalken des Südslowakischen Karstes zweifellos von einer Serie pannonischer Sedimente überlagert (J. Kubišta, R. Marschalko \& L. RozlozsniK 1953) und ist also offenbar vorpliozänen Alters. Noch älter sind die Terra-rossa-Bildungen auf den Devonkalken bei Hranice (Weißkirchen) in der Mährischen Pforte, deren Hangendes marines Torton bildet (V. Rousex \& J. VRB. 1960). Dadurch ist das tertiäre Alter 
einer ganzen Reihe von Terra rossa-Vorkommen sicher belegt, während fast keine Beweise eines geringeren, d. h. quartären Alters, zur Verfügung stehen.

Große Möglichkeiten für die Altersbestimmung von Terrae calcis bi e te t die Un tersuchung der Böden a uf Travertinen verschiedenen Alters. Während typisch ausgebildete Terra rossa-Böden bisher nur auf pliozänen Travertinen festgestellt wurden, gibt es verhältnismäßig zahlreiche Terra fusca-Vorkommen auf Travertinen aus allen pleistozänen Interglazialen, nicht aber aus dem Postglazial. Über diese Beobachtungen wurden bisher nur kurze allgemeine Angaben veröffentlicht (V. LožEK \& Fr. Prošex 1957, V. Ložek 1959, V. Ložek \& J. TyráčEk 1958 usw.). Aus ihnen ergibt sich aber, daß die meisten Bildungen der Terra rossa beträchtlich älter als die der Terra fusca sind, die gewöhnlich noch in den pleistozänen Warmzeiten entstanden. Die Terra rossa-Bildung endete in Mitteleuropa bereits zu Beginn des Quartärs.

Hier soll versucht werden, folgende Fragen zu beantworten:

a) Wie alt sind die jüngsten Terra rossa-Bildungen Mitteleuropas und welche Terra rossa-Formen liegen hier vor?

b) In welchen Zeitabschnitten bildetesich Terrafusca und in welchem Umfang?

c) Möglichkeiten der Terra fusca-Bildung im Postglazial.

d) Bedeutung von Terrae calcis für die Quartärstratigraphie und -paläoklimatologie und deren Korrelation mit anderen Quartärablagerungen, bzw. Böden.

\section{Stellung der Terrae calcis im quartären stratigraphischen System}

Wenn die Position von Terrae calcis im quartären Sedimentations- und Bodenbildungszyklus festgestellt werden soll, muß man sich auf die Korrelation der Klimabedingungen, unter welchen sich die Bildung dieser Böden vollzieht, mit den Schwankungen des Quartärklimas stützen. Im allgemeinen kann man sagen, daß Terrae calcis das Produkt eines warmen feuchteren Klimas sind. Bei Terra fusca wird ein mäßig warmes und feuchtes Klima vorausgesetzt, das dem heutigen entspricht, bzw. ein wenig wärmer ist. Die Terra rossa beansprucht dagegen ein wärmeres Klima als das heutige im mitteleuropäischen Raum. Insbesondere ist hierzu ein heißer warmer Sommer und eine intensive Erwärmung des Bodenmaterials notwendig. Aus dem Vergleich dieser Voraussetzungen mit den bisherigen Erkenntnissen über den Charakter der quartären Klimaschwankungen geht somit hervor, daß nur solche Schwankungen in Betracht gezogen werden können, die mindestens so warm und feucht waren wie die heutige Zeit - also echte Interglaziale (vgl. J. KukLA \& V. LožEK 1961, J. KuKLA 1961). Die Kaltzeiten können im voraus ausgeschlossen werden. Auch die Möglichkeit einer Terra fusca-Bildung in großen Interstadialen - wenn auch nur im beschränkten Umfang - erscheint wenig wahrscheinlich. Aus den Analysen der mitteleuropäischen interglazialen Vertebraten- und Molluskenfaunen ist ersichtlich, daß die Interglaziale der jüngeren Hälfte des Pleistozäns in ihrer Gipfelphase wärmer und wesentlich feuchter als die heutige Zeit waren. Sie boten sehr günstige Bedingungen für die Terra fusca-Bildung. Die Möglichkeit von Terra rossa-Entstehung dürfte allerdings sehr beschränkt gewesen sein. Die altpleistozänen Warmzeiten waren noch wärmer, und ein wechselfeuchtes Klima mit heißem Sommer machte sich offenbar stärker geltend. In diesen Fällen kann die Terra rossa-Bildung nicht ausgeschlossen werden, insbesondere wenn man Befunde an einigen Fundstellen in Betracht zieht.

Zur Bestimmung der stratigraphischen Position und des Alters von quartären Terrae calcis stehen einige Kriterien zur Verfügung (vgl. H. KLINGE 1956, 1958, L. SMoLíková 1961a):

1. Das Alter des A usgangsgesteins (vgl. Abb. 1, 2, 3, 4, 5, 7, 8). Die untere Altersgrenze von Terrae calcis ist am besten dort bestimmt, wo das Alter des Aus- 
gangsgesteins genau bekannt ist und wo eine sekundäre Herkunft von Terrae calcis-Material ausgeschlossen werden kann. Beste Möglichkeiten bieten hier Travertine verschiedenen Alters im karpatischen Raum, namentlich in der Slowakei (V. Ložek \& Fr. Prošek 1957). Die Travertine bildeten sich in diesem Gebiet im Pliozän, in den pleistozänen Interglazialen, sowie im Postglazial (V. LožEK 1961c). Sie treten morphologisch im allgemeinen als auffallende Kuppen auf, deren Umgebung oft von Gesteinen aufgebaut ist, die kein günstiges Substrat für die Terrae calcis-Bildung bieten (Sandsteine und Tonschiefer des Paläogens), so daß eine allochthone Herkunft von Terrae calcis-Material auf den Travertinen vollkommen ausgeschlossen ist.

Das Alter des Travertins bestimmt die untere Zeitgrenze des möglichen Beginns der Terrae calcis-Bildung. Durch den Vergleich dieser Böden aus Travertinen von verschiedenen Zeitabschnitten kann somit annähernd festgestellt werden, welche Böden in verschiedenen Perioden entstanden und welche Entwicklungsstufe sie erreichten. Außer den Travertinen bieten auch Kalkbreccien ein günstiges Ausgangsmaterial, die mit Sinter verkittet sind (V. LožEK 1960). Terrassen und Moränen aus reinem Karbonatmaterial stehen im tschechoslowakischen Raum nicht zur Verfügung.

2. Das Verhältnis zur quartären Erosion (Abb. 6). Dieses Kriterium kann in solchen Gebieten benützt werden, in denen ein Kalkgelände durch Täler gegliedert ist. Diese wurden im Verlauf des Quartärs durch Erosion stufenweise gebildet, vor allem im Bereich der Böhmischen Masse. Wenn die Zeitbestimmung der einzelnen Erosionsniveaus festgelegt ist, kann eine ähnliche Methode wie im Falle der Travertine verwendet werden. Hier bestehen allerdings nur beschränkte Möglichkeiten, da geeignete Untersuchungsstellen ziemlich selten sind und eine allochthone Entstehung von Terrae calcis nicht völlig ausgeschlossen werden kann, weil ihr Material von höheren Abschnitten der Kalkhänge angeschwemmt wird.

3. Terrae calcis-Sedimente in Ausfüllungen der Karsthohlr ä u me. Das Bodenmaterial kann in die Karsthohlräume während verschiedenster Zeitabschnitten angeschwemmt werden, so daß die einzelnen Beobachtungen nicht maßgebend sein können. Man kann aber die Ausbildung von genau datierten Ausfüllungen verschiedenen Alters vergleichen (M. KREtzor 1956) und daraus schließen, welche Böden auf der Oberfläche der Kalkgebiete in den betreffenden Zeiträumen vorherrschten. Obwohl solche Beobachtungen sehr vorsichtig gewertet werden müssen, können sie doch ein gutes Hilfsmittel sein.

4. Das gegenseitige Verhältnis verschiedener Typen und Varietäten von Terrae calcis in den Profilen (Abb. 9). Steht eine größere Anzahl von Profilen in einem bestimmten Gebiet zur Verfügung, so können gesetzmäßige Beziehungen verschiedener Typen von Terrae calcis festgestellt werden, $z$. B. von Terra rossa zu Terra fusca. Die Terra rossa tritt z. B. nur in Ausfüllungen von tieferen Korrosionshohlräumen auf, während die Terra fusca regional an der Oberfläche verbreitet ist (vgl. L. Smolíková 1961b). Thre Sedimente überlagern gewöhnlich die Terra rossaAusfüllungen der Hohlräume. Daraus ist ersichtlich, daß die Terra rossa-Böden im betreffenden Gebiet älter als die Terra fusca sind.

Im folgenden Abschnitt unseres Beitrages werden die datierbaren Vorkommen von Terrae calcis im tschechoslowakischen Gebiet in der Zeitspanne Pliozän-Quartär besprochen. Wir werden die Aufmerksamkeit auf solche Fundstellen richten, in denen die untere Altersgrenze durch das Ausgangsmaterial bestimmt wird, also vor allem auf die Travertine.

Die meisten hier erörterten Terrae calcis-Profile wurden labormäßig untersucht. Ein Teil der Dünnschliffe wurde in der bodenkundlichen Abteilung der Bundesforschungsanstalt für Forst- und Holzwirtschaft, Reinbek bei Hamburg, hergestellt, die eingehenden 


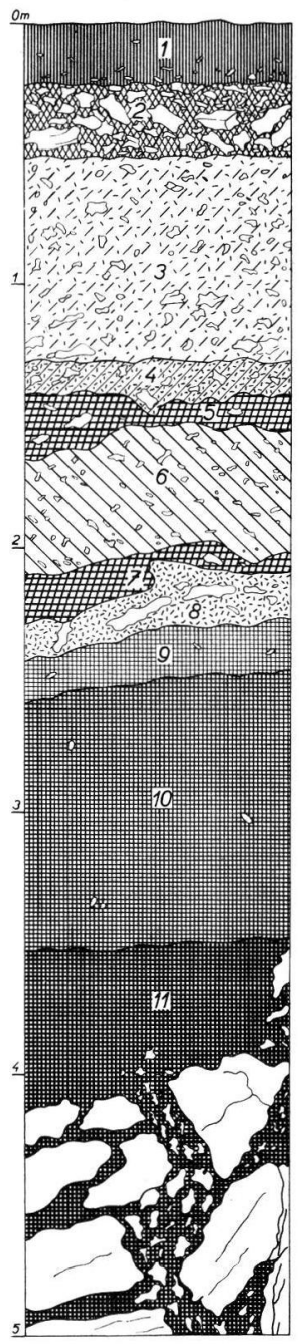

Abb. 1. Dreveník-Ostrá hora, Deckschichtenprofil an der Ostwand des Travertinsteinbruchs. - 1 Oberflächenboden (Mullrendsina, 10 YR 4/2), 2-8 Schuttschichten: 2 Zwischenmittel mit toniger Beimengung, vermutlich Terra fusca-Material (10 YR 5/6), 3, 4, 6 scharfkantiger bis mäßig korrodierter Travertinschutt mit lößartigem $Z_{w i-}$ schenmittel (10 YR 6/3 - 7/4), 5, 7 Zwischenlagen von Terra rossa-Sedimenten (2,5 YR 4/5 - 4,5/6); 8 heller Kalkanreidıerungshorizont (10 YR 8/4), 9-11 braunrote tonige Lehme - Terra rossa; 9 u. 10 z. T. umgelagert (2,5 YR 4/5 - 4/6); 11 (2,5 YR 4/8) liegt unmittelbar dem stark korrodierten, festen, weißen Travertin auf.

Analysen der Terra fusca-Profile von Lúčky und Bojnice sowie die Dünnschliffe von diesen Fundstellen haben die Laboratorien des VEB Geologische Erkundung Süd-Freiberg/Sachsen durchgeführt. Für diese freundliche Hilfe sind die Verfasser den Herren Prof. Dr. W. L. Kubiena, Hamburg-Reinbek, und Dr. Manfred WüNsche, Freiberg/Sa. zu größtem Dank verpflichtet.

\section{Jungpliozäne und quartäre Terrae calcis-Vorkommen im tschechoslowakischen Gebiet}

\section{Terra rossa}

Die jüngsten einwandfrei datierten Terra rossa-Vorkommen entstanden aus Travertinen. Bisher sind folgende drei Fundstellen bekannt:

Dreveník-Ostrá hora bei Spišské Podhradie (=Kirchdrauf). Der mächtige Komplex von Dreveník und Ostrá hora besteht aus harten porösen Travertinen weißer Färbung, in welchen eine pliozäne Flora (F. Ň̌mEjc 1944) und die Mollusken 
Abida frumentum (DRAP.) und Fruticicola fruticum (MüLL.) festgestellt wurden. Der Travertin bildet ein ganzes Kuppensystem, das seine Umgebung als ein gewelltes Plateau mit schroffen, durch Rutschungen gestörten Rändern hoch überragt. Die weite Umgebung ist von paläogenen Sandsteinen und Tonschiefern aufgebaut. Die Terra rossa ist auf dem Dreveník-Plateau an zahlreichen Stellen in verkarsteten Spalten erhalten. Am besten können ihre Lagerungsverhältnisse im großen Steinbruch am Westhang eines flachen Sattels zwischen Ostrá hora und Dreveník verfolgt werden. Dort sind nur schwache Abtragungen zu verzeichnen, so daß die Abbauwand beste Aufschlüsse bietet.

Im Bereich des Sattels bildet eine siallitisch-allitische Terra rossa $\frac{\mathrm{SiO}_{2}}{\mathrm{Al}_{2} \mathrm{O}_{3}+\mathrm{Fe}_{2} \mathrm{O}_{3}}$ $\left.=0,13-0,19)^{1}\right)$ eine fast zusammenhängende Decke auf der stark korrodierten Travertinoberfläche (Abb. 1) und füllt auch zahlreiche, bis mehrere Meter tiefe Verwitterungstaschen aus. Sie ist von einem Schutt mit gelblichem lehmigem $Z$ wischenmittel überlagert, der durchsinterte $Z_{\text {wischenlagen }}$ und Einlagerungen von Terra rossa-Sedimenten aufweist. Der Oberflächenboden ist heute eine tiefgründige Mullrendsina. Die erwähnten Schuttbildungen stellen zweifellos ein Produkt der pleistozänen Kaltzeiten dar.

In der Ostwand des Steinbruches gibt es Höhlungen, die mit Terra rossa-Material ausgefüllt sind, das sich von der zusammenhängenden Terra rossa-Decke der Oberfläche unterscheidet. Im Nordabschnitt der Wand wurde in einer kleinen Höhle etwa $4 \mathrm{~m}$ unter der Travertinoberfläche eine satt-rote, wenig plastische, krümelige allitische Terra rossa $\left(\frac{\mathrm{SiO}_{2}}{\mathrm{Al}_{2} \mathrm{O}_{3}+\mathrm{Fe}_{2} \mathrm{O}_{3}}=0,12\right)$ festgestellt (Probe $\left.\mathrm{B}\right)$. In einer größeren Höhle am Fuß der Wand unter dem Oberflächenprofil (A) befindet sich eine rötlich braune Ausfüllung mit häufigem Bohnerz (Probe C), die als Sediment einer ausgeprägt allitischen Terra rossa $\frac{\mathrm{SiO}_{2}}{\mathrm{Al}_{2} \mathrm{O}_{3}+\mathrm{Fe}_{2} \mathrm{O}_{3}}$ $=0,02)$ gewertet werden kann.

Aus den angeführten Punkten geht hervor, daß sich die Terra rossa-Bildung in diesem Raum in mehreren Generationen vollzog. Die ausgeprägt allitischen Terra rossa-Formen in tiefen Hohlräumen sind offenbar älter als die schwächer allitische Terra rossa-Decke auf der Travertinoberfläche. Die Entstehung dieser Böden fällt zweifellos in das Endpliozän und in die Warmzeiten des ältesten Pleistozäns, da auf benachbarten Travertinen, die ähnlichen Charakter und Lagerungsverhältnisse wie der Travertin von Dreveník aufweisen, bisher keine Terra rossa nachgewiesen wurde, abgesehen von atypischen Resten rötlicher Bodenbildungen auf der altpleistozänen Pažica.

Zlatý Onyx bei Levice. Der sogenannte "goldene Onyx" ist tatsächlich ein kompakter gelber Travertin mit zahlreichen kristallinischen Partien. Er bildet eine flache Kuppe auf dem Rücken der Levicer Weinberge sïdlich von der Stadt Levice und wurde von L. IvaN (1952) in das Quartär eingeordnet. Ein altquartäres Alter kann zwar nicht ausgeschlossen werden, es handelt sich jedoch viel wahrscheinlicher um Jungpliozän.

Die gesamte aufgeschlossene Travertinwand, die etwa $10 \mathrm{~m}$ hoch ist, wird von zahlreichen Korrosionshohlräumen durchsetzt, die mit satt-rotem Ton gefüllt sind. Sein Gefüge ist breccienartig und das Verhältnis $\frac{\mathrm{SiO}_{2}}{\mathrm{Al}_{2} \mathrm{O}_{3}+\mathrm{Fe}_{2} \mathrm{O}_{3}}=0,11-0,12$ entspricht einer allitischen Terra rossa. Im Hangenden liegt eine komplizierte Lößserie mit zwei fossilen Bodenkomplexen (Abb. 2). Die Korrosion der Travertine ist sehr stark und tief.

Aus der Ausbildung des Deckprofils ergibt sich, daß die Terra rossa hier mindestens vor zwei Interglazialen entstanden ist, denen die erwähnten fossilen Bodenkomplexe an-

1) Werte nach dem Auszug mit heißer $20 \% \mathrm{HCl}, \mathrm{SiO}_{2}=\mathrm{SiO}_{2}$ in $\mathrm{HCl}+\mathrm{SiO}_{2}$ in $\mathrm{KOH}$. 


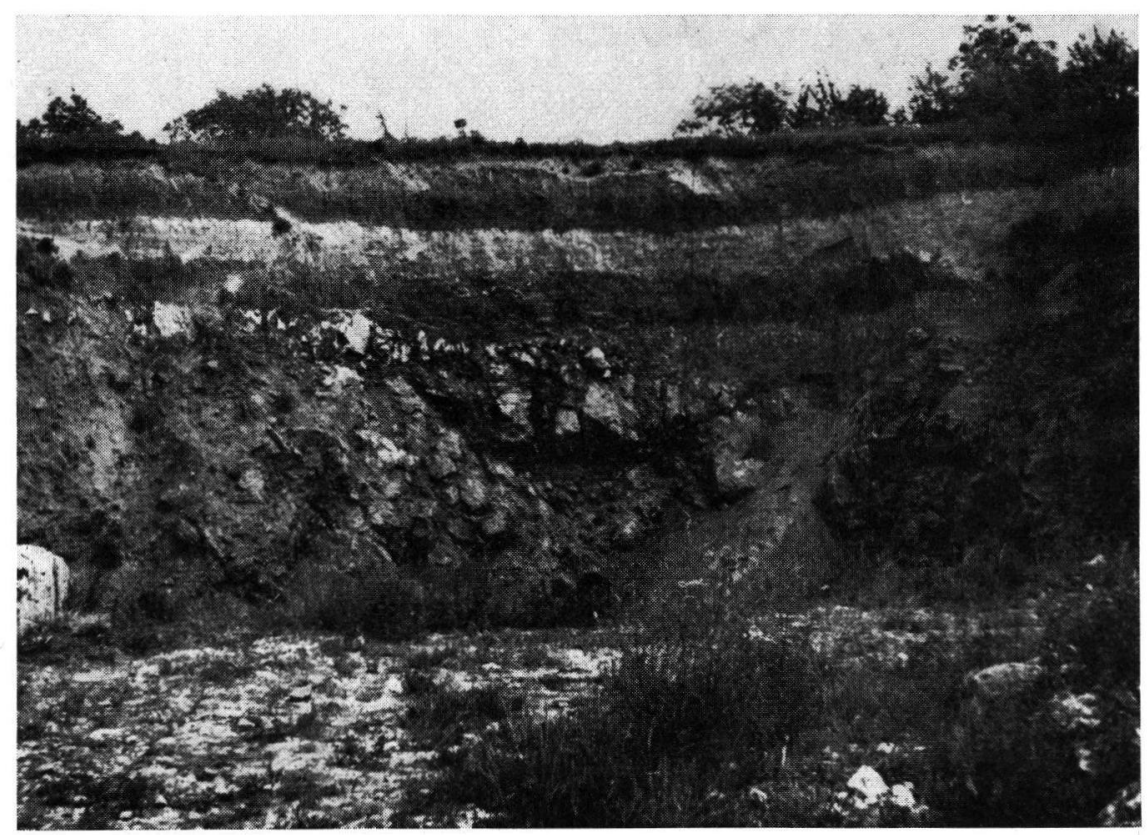

Abb. 2. Goldener Onyx bei Levice, Ostwand der oberen Grube. - Der untere Abschnitt der Abbauwand besteht aus festem, von zahlreichen Korrosionshohlräumen durchsetztem Travertin, die mit Terra rossa (roter Ton, $10 \mathrm{R} \mathrm{4/6} \mathrm{-} \mathrm{3/8)} \mathrm{ausgefüllt} \mathrm{sind.} \mathrm{Darüber} \mathrm{lagert} \mathrm{eine} \mathrm{komplizierte} \mathrm{Löß-}$ serie mit zwei fossilen Bodenkomplexen.

Foto: Vojen LožEK.

gehören. Man muß auch den Umstand in Betracht ziehen, daß sich das Profil an einer exponierten Stelle befindet. Daraus ist zu schließen, daß hier nicht Interglaziale vorliegen, die unmittelbar dem Postglazial voranstehen und daß die Lößserie von den Terra rossa-Bildungen durch eine Diskordanz getrennt ist.

Ratnovce bei Piešt'a ny. Travertine, die im großen Steinbruch bei Ratnovce aufgeschlossen sind, gehören altersmäßig zweifellos in das Neogen (vgl. O. HyNiE 1927). Ihre Oberfläche ist mit zahlreichen tiefen Korrosionshöhlen durchsetzt, die vorwiegend mit satt-braunen, stellenweise gelb gefleckten und gebänderten Tonen ausgefüllt sind. Ơrtlich sind auch tiefe Verwitterungstaschen mit rotem Ton vorhanden. Die Deckschichten können nicht verfolgt werden, da sie durch den Abbau gestört wurden.

Travertine, auf denen eine Terra rossa festgestellt wurde, sind durchweg alt, das heißt im Falle von Dreveník und Ratnovce nachweisbar pliozän, im Falle von Levicer Onyx ist dieses Alter äußerst wahrscheinlich. Bald nach ihrer Entstehung wurden sie durch intensive chemische Verwitterung angegriffen, deren Produkt die tiefen Korrosionshöhlen und die Terra rossa sind. Die pleistozänen Schichten, wie Löß, Schutt und fossile Böden, sind von der liegenden Terra rossa durch eine Diskordanz getrennt. Die älteste mögliche Entstehungszeit der besprochenen Terra rossa-Böden ist in Anbetracht des Alters der Muttergesteine das Spätpliozän, bzw. die Warmzeiten des ältesten Pleistozäns. Jüngere Zeitabschnitte können ausgeschlossen werden, da die Terra rossa in typischer Ausprägung bisher auf keinem pleistozänen Travertin nachgewiesen wurde. Dieser Boden läßt sich nicht einmal in der nächsten Nachbarschaft der oben erwähnten Vorkommen finden, in denen alle Entstehungsmöglichkeiten gleich waren, abgesehen vom Alter des Ausgangsgesteins.

Für die Altersbestimmung der Terra rossa sind in einigen Fällen auch die Ausfüllungen 
der Karsttaschen von Bedeutung. Dazu bietet die besten Bedingungen der Steinbruch an der Anhöhe Skala bei Ivanovce im Waagtal.

Die mesozoischen Kalke von Skala sind mit einem komplizierten System von Karsthohlräumen durchsetzt, die mit gelbbraunem Ton mit Bohnerz gefüllt sind. Dieses Material enthält eine reiche Wirbeltierfauna, die altersmäßig an die Grenze Pliozän/Pleistozän fällt (O. Fejfar 1961a). Außer dieser älteren Generation von Karsttaschen gibt es hier auch Korrosionshöhlen mit roter Ausfüllung ohne Bohnerz, die zweifellos jünger sind. Rote Tone wurden auch in die Ausfüllung einer alten Doline umgelagert, die im Steinbruch am Nordhang von Skala aufgeschlossen ist. Der besprochene Komplex wird von einer Lößserie mit fossilen Böden und von postglazialen Schichten mit häufiger prähistorischer Keramik überlagert. In den roten Ausfüllungen wurde eine typisch pleistozäne interglaziale Molluskenfauna nachgewiesen.

Aus den stratigraphischen Verhältnissen des Aufschlusses von Ivanovce geht klar hervor, daß die rote Ausfüllung altpleistozänen Alters ist und daß sie in einem Interglazial entstand, dessen nähere Einstufung noch offenbleiben muß.

Eine ähnliche Fundstelle ist die Anhöhe Málok bei Koliňa n y (NO von Nitra), deren Kalke zahlreiche, mit Terra rossa gefüllte, einander parallele Spalten aufweisen. Alle Ausfüllungen führen eine einheitliche altpeistozäne Wirbeltierfauna mit Beremendia fissidens (Pet.), Prospalax priscus (Nehr.), Hypolagus beremendensis Korm. usw. (O. Fejfar 1961b), woraus zu schließen ist, daß die Ausfüllung der Spalten während einer relativ kurzen Zeitspanne erfolgte. Auf der Oberfläche tritt hier heute keine Terra rossa auf.

Diese Beobachtungen stimmen mit den Befunden aus dem Südslowakischen Karst überein, wo durch reiche altpleistozäne interglaziale Mollusken- und Wirbeltierfaunen belegte Terra rossa-Sedimente in Karsttaschen bei Gombasek, Plešive c und J elšava festgestellt wurden. Die Beschaffenheit der Ausfüllungen bietet allerdings keinen festen Beweis für das altpleistozäne Alter der Terra rossa. Diese konnte als Sediment in verschiedensten Zeitabschnitten umgelagert werden (z. B. während der Würm-Eiszeit, wie in der Großen Jasover Höhle festgelegt wurde - V. LožEK, J. Sekyra, J. Kukla \& O. FEJFAR 1957). Es ist hier doch offensichtlich, daß in der betreffenden Zeit die Terra rossa-Böden auf der Karstoberfläche regional verbreitet waren und wahrscheinlich auch noch gebildet wurden. Dasselbe bestätigen auch Befunde aus Ungarn (M. Kretzor 1956), sowie einige auffallend rote Schichten in cromer-zeitlichen Serien von Zlatý Kůn und von Chlum bei Srbsko im Böhmischen Karst.

Aus den angeführten Punkten geht somit hervor, daß die jüngsten sicher belegten Terra rossa-Vorkommen zeitlich in das oberste Pliozän und in die Warmzeiten des ältesten Pleistozäns fallen. Es handelt sich hierbei sowohl um deutlich allitische als auch siallitische Formen von Terra rossa.

Bisher ist nicht klar, ob sich die Terra rossa wenigstens örtlich und im beschränkten Umfang auch später bilden konnte. Einige Befunde dürften dafür zeugen. Es fehlen hierfür jedoch genügende Beweise. Erwähnenswert sind z. B. unzweifelhafte Terra rossaSedimente aus der interglazialen Serie im Südeingang der Dudlavá Ska la - Höhle bei Šumia c, Zentralslowakei (V. LožEK 1962). Auf Grund der spärlichen Wirbeltierfunde und der Position im Hangenden der Hauptgeneration von Gebirgsrandschottern der Niederen Tatra ist dieses Interglazial nicht älter als Holstein. Die Fundstelle liegt im Gebirge, wo mehrmals eine sehr starke Abtragung stattgefunden hat. Heuzutage gibt es an der Oberfläche keine Terra rossa mehr. Danach darf man vermuten, daß sie während des erwähnten Interglazials an der Oberfläche noch weit verbreitet war und angesichts der angeführten Umstände nicht ein Relikt aus viel älteren Zeiten darstellen konnte. 


\section{Terrafusca}

Die Terra fusca wurde auf relativ zahlreichen Travertinlagern im Karpatenraum festgestellt. Hier sollen in kurzer chronologischer Übersicht die einzelnen Vorkommen besprochen werden:

\section{Altpleistozäne Travertine}

Malé Bielice im Nitra Tal. Auf annähernd horizontal gelagerten kompakten Süßwasserkalken mit einer reichen interglazialen Molluskenfauna (T. Kormos 1911) ist eine mächtige Terra fusca ausgebildet, die in tiefen Verwitterungsorgeln in das Muttergestein eingreift (V. LožEK \& Fr. PвоšEK 1957). Sie liegt direkt dem anstehenden Kalk auf und ist zum Teil von Löß überlagert.

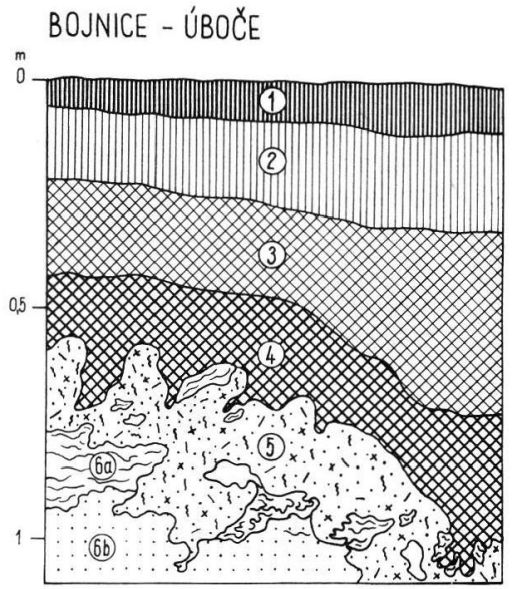

Abb. 3. Bojnice-Úboče, T. fusca aus altpleistozänem Travertin. 1 Dunkel graubrauner (10 YR 3/3), humoser Lehm, gut krümelnd, wurzelfilzig, 2 dunkelbrauner $(8,75$ YR 4/4), humoser, \pm krümeliger Lehm mit verstreutem feinem Travertinschutt $(<2 \mathrm{~cm})$, vereinzelte Holzkohlen (wahrscheinlich ein ehemaliger Ap-Horizont), 3 brauner (7,5 YR 4,5/4), z. 'T. humusfleckiger, stark toniger Lehm, mittelblockig, im feuchten Zustand plastisch, schwach durchwurzelt, 4 rötlichbrauner (5 YR 4/4,5), stärker toniger Lehm, großblockig aufbrechend, stark plastisch, 5 verwitterter Travertin und feiner Travertinsand (10 YR 6/3 u. 5/3), feine, mit dem hangenden Ton ausgefüllte Korrosionsorgeln und zahlreiche Toneinschlämmungen, die auch die Poren im festen Travertin auskleiden; verwitterte, stark tonige und relativ frische Partien sind unregelmäßig verteilt, 6 hell gelbbrauner (10 YR 6/4), feiner Travertinsand mit Lagen und Knollen festen feinporigen Travertins (10 YR 8/4) (vgl. Tabelle 1).

Bojnice an der oberen Nitra (Abb. 3, Tab. 1). Auf den Travertinen „Ú b o č e“ am Zoologischen Garten befindet sich eine mächtige rotbraune Terra fusca (V. LožEK 1961b). Sie liegt unmittelbar den oberen lockeren Schichten auf, zum größten Teil unter Acker. Die Ackerkrume weist eine sekundäre Kalkanreicherung auf; der Unterboden ist aber eine sehr typische Terra fusca mit zungenartigen Ausläufern in das Muttergestein. Hier muß hervorgehoben werden, daß auf den benachbarten Travertinen am Kirchhof, die wahrscheinlich letztinterglazial sind, bisher keine Terra fusca nachgewiesen wurde, obwohl beide Standorte hinsichtlich der bodenbildenden Faktoren fast vollkommen übereinstimmen.

Vyšné Ružbachy in der Zips. Auf der Travertinkuppe Modzele ist eine sattbraune tiefgründige Terra fusca zu verzeichnen. Sie liegt unmittelbar dem frischen Muttergestein auf.

Hier sei auch auf das Terra fusca-Vorkommen auf den Travertinen der Anhöhe Gestence bei Dudince erwähnt, das bisher noch nicht näher untersucht wurde.

\section{Mittelpleistozäne Travertine}

Tučín bei Př e rov (Prera u). Eine sattbraune Terra fusca erscheint unmittelbar über den oberen lockeren Schichten einer Travertinkuppe. In ausgeprägten Verwitterungstaschen greift sie bis $1,5 \mathrm{~m}$ tief in das Muttergestein. Stellenweise ist sie von Hangmaterial mit Detritus der Tertiärsandsteine und äolicher Beimischung überlagert. Dort, wo der Travertin vom Travertinschutt überlagert ist, der kryoturbat gestört wurde, liegt keine Terra fusca vor (V. LožEk \& J. TYróčEk 1958). Daraus kann geschlossen werden, daß sie bereits hohes Alter besitzt. 
Tabelle 1

Ergebnisse der chemischen Analysen und der Korngrößenbestimmung von Terra fusca-Profilen

Chemische

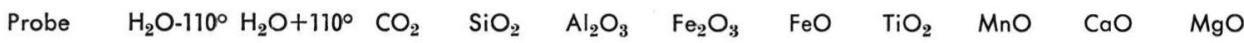

\begin{tabular}{|c|c|c|c|c|c|c|c|c|c|c|c|}
\hline B 1 & 3,3 & 6,7 & 7,0 & 52,7 & 10,9 & 4,1 & 0,2 & 0,8 & 0,09 & 10,4 & 1,3 \\
\hline B 2 & 3,9 & 5,6 & 5,5 & 58,0 & 12,1 & 4,8 & 0,2 & 0,8 & 0,08 & 7,8 & 1,3 \\
\hline B 3 & 4,8 & 5,7 & 0,5 & 63,5 & 16,5 & 6,0 & 0,1 & 0,9 & 0,08 & 1,9 & 1,2 \\
\hline B 4 & 7,1 & 7,2 & 1,5 & 57,6 & 17,0 & 7,6 & 0,1 & 0,9 & 1,0 & 2,3 & 2,2 \\
\hline B 5 & 0 & 7,8 & 20,4 & 27,4 & 8,9 & 4,1 & 0 & 0,5 & 0,06 & 27,4 & 1,5 \\
\hline B $6 a$ & 0 & 1,3 & 40,6 & 1,0 & 0,9 & 0,3 & 0 & 0,1 & 0,02 & 51,6 & 1,6 \\
\hline B $6 b$ & 0,2 & 1,2 & 40,8 & 1,4 & 0,6 & 0,2 & 0,1 & 0,5 & 0,03 & 52,6 & 1,8 \\
\hline - & & & - & & & & & & & & \\
\hline L 1 & 1,8 & 4,7 & 0,3 & 67,4 & 13,1 & 4,3 & 0,8 & 0,9 & 0,10 & 1,1 & 2,5 \\
\hline L 2 & 5,9 & 7,7 & 0 & 56,5 & 19,5 & 7,5 & 0,5 & 0,8 & 0,09 & 1,6 & 0,9 \\
\hline L 3 & 4,4 & 6,0 & 0,2 & 55,8 & 19,6 & 8,1 & 0,2 & 1,0 & 0,09 & 2,8 & 2,8 \\
\hline L 4 & 5,9 & 10,2 & 0,03 & 51,0 & 21,5 & 8,9 & 0,4 & 0,8 & 0,09 & 1,7 & 2,2 \\
\hline L 5 & 1,8 & 2,8 & 30,9 & 13,4 & 6,1 & 3,1 & 0,1 & 0,2 & 0,04 & 41,0 & 1,1 \\
\hline
\end{tabular}

Die Werte beziehen sich auf bei $110^{\circ}$ getrocknete Substanz, das $\mathrm{H}_{2} \mathrm{O}-110^{\circ}$ ist infolgedessen in der

\begin{tabular}{|c|c|c|c|c|c|c|}
\hline & & & & & & Korn \\
\hline Probe & $20,0-6,3$ & $6,3-2,0$ & $2,0-1,0$ & $1,0-0,63$ & $0,63-0,20$ & $0,20-0,10$ \\
\hline B 1 & - & - & 1,2 & 1,6 & 5,1 & 3,5 \\
\hline B 2 & 1,0 & 0,3 & 0,3 & 0,7 & 2,9 & 2,4 \\
\hline B 3 & - & - & 0,4 & 0,5 & 1,1 & 0,6 \\
\hline В 4 & - & 0,6 & 0,4 & 0,6 & 1,2 & 0,4 \\
\hline B 5 & 1,4 & 2,4 & 4,7 & 4,0 & 10,1 & 5,4 \\
\hline B $6 b$ & - & - & 2,2 & 3,1 & 12,1 & 12,6 \\
\hline-- & - - & --- & -- & --- & --- & ----- \\
\hline L 1 & - & - & 0,2 & 0,7 & 4,0 & 8,0 \\
\hline L 2 & - & - & 0,2 & 0,6 & 3,1 & 4,2 \\
\hline L 3 & - & - & 0,3 & 0,9 & 3,2 & 3,2 \\
\hline L 4 & - & - & - & 0,2 & 1,3 & 1,0 \\
\hline L 5 & - & - & 1,7 & 4,0 & 13,4 & 10,1 \\
\hline
\end{tabular}

Von der Probe B 6a wurde keine Kornanalyse durchgeführt, da die Probe, ein Travertin, sich auf Die Kornanalysen der Proben B 5, B 6b und L 5 sind durch den hohen $\mathrm{CaCO}_{3}$-Gehalt in der Weise

B = Bojnice-Ûboče, $\mathrm{L}=$ Lúčky-Skaličky 
Bojnice-Úboče und Lúčky-Skaličky

\begin{tabular}{|c|c|c|c|c|c|c|c|c|c|c|c|}
\hline \multicolumn{12}{|c|}{ Analysen } \\
\hline $\mathrm{K}_{2} \mathrm{O}$ & $\mathrm{Na}_{2} \mathrm{O}$ & $\mathrm{P}_{2} \mathrm{O}_{5}$ & $\mathrm{~s}$ & $\begin{array}{l}\text { Org. Subst. } \\
\text { (Humus) }\end{array}$ & 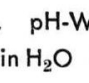 & $\begin{array}{l}\text { Nert } \\
\text { in } \mathrm{KCl}\end{array}$ & $\begin{array}{l}\text { (T-S)- } \\
\text { Wert }\end{array}$ & S-Wert & T-Wert & V-Wert & $\begin{array}{c}\mathrm{CaCO}_{3} \\
\text { nach SCHEIBLER }\end{array}$ \\
\hline 1,5 & 0,6 & 0,18 & 0,15 & 3,5 & 7,41 & 7,1 & 5,87 & 27,55 & 33,42 & 82,25 & 12,25 \\
\hline 1,6 & 0,6 & 0,16 & 0,02 & 1,3 & 7,68 & 7,2 & 6,25 & 27,8 & 34,05 & 81,6 & 9,05 \\
\hline 1,8 & 0,8 & 0,08 & 0,08 & 0,5 & 7,65 & 7,0 & 6,25 & 32,4 & 38,65 & 83,85 & 0,45 \\
\hline 1,7 & 0,4 & 0,06 & 0,04 & 0,7 & 7,58 & 6,85 & 9,5 & 44,5 & 54,00 & 82,4 & 3,95 \\
\hline 0,8 & 0,2 & 0,17 & 0,13 & 0,8 & 7,8 & 7,2 & 5,37 & 29,2 & 34,57 & 84,45 & 40,4 \\
\hline 0,2 & 0,2 & 0,36 & 0,33 & 1,4 & 8,55 & 8,4 & 0,25 & 18,6 & 18,85 & 98,55 & 77,9 \\
\hline 0,2 & 0,1 & 0,38 & 0,54 & 0,3 & 8,42 & 8,4 & n. g. & 7,45 & 7,45 & 100,00 & 76,5 \\
\hline- - & - & - & -- & -- & -- & -- & -- & -- & -- & - & ---- \\
\hline 2,2 & 0,6 & 0,05 & 0,70 & 1,6 & 7,70 & 7,15 & 5,87 & 17,65 & 23,52 & 75,0 & 1,2 \\
\hline 3,4 & 0,5 & 0,08 & 0,02 & 1,2 & 7,68 & 6,85 & 8,75 & 32,35 & 41,10 & 78,7 & Spuren \\
\hline 2,3 & 0,4 & 0,12 & 0,13 & 0,2 & 7,85 & 6,70 & 9,37 & 36,1 & 45,47 & 79,4 & Spuren \\
\hline 2,3 & 0,3 & 0,07 & 0,04 & 0,3 & 7,80 & 6,75 & 10,12 & 46,0 & 56,12 & 81,95 & Spuren \\
\hline 0,6 & 0,1 & 0,23 & 0,26 & 0,3 & 8,25 & 7,4 & 3,5 & 18,1 & 21,6 & 83,8 & 54,8 \\
\hline
\end{tabular}

Summe nicht enthalten.

\begin{tabular}{|c|c|c|c|c|c|c|}
\hline \multicolumn{7}{|l|}{$\mathrm{g} r o ̈ ß$ e $n$} \\
\hline $0,10-0,063$ & $0,063-0,020$ & $0,020-0,010$ & $0,010-0,006$ & $0,006-0,002$ & $<0,002 \mathrm{~mm}$ & $\%$ \\
\hline 3,8 & 20,7 & 20,6 & 4,0 & 7,5 & 30,4 & 98,4 \\
\hline 2,7 & 17,3 & 24,0 & 2,2 & 6,7 & 38,7 & 99,2 \\
\hline 2,4 & 17,8 & 13,5 & 9,0 & 8,1 & 44,3 & 97,7 \\
\hline 0,8 & 7,4 & 13,9 & 7,2 & 5,5 & 61,8 & 99,8 \\
\hline 5,7 & 9,5 & 6,7 & 4,0 & 6,4 & 37,2 & 97,5 \\
\hline 19,1 & 23,5 & 10,4 & 4,5 & 6,2 & 6,1 & 99,8 \\
\hline--- & --- & --- & --- & --- & -- & -- \\
\hline 12,5 & 18,2 & 7,1 & 4,8 & 10,3 & 33,2 & 99,0 \\
\hline 6,0 & 10,4 & 4,8 & 2,7 & 8,0 & 57,9 & 97,9 \\
\hline 5,5 & 5,3 & 5,4 & 5,9 & 7,3 & 60,6 & 97,6 \\
\hline 2,5 & 5,9 & 4,2 & 2,4 & 9,1 & 72,1 & 98,7 \\
\hline 10,4 & 14,4 & 8,5 & 3,2 & 8,8 & 25,4 & 99,9 \\
\hline
\end{tabular}

Grund des hohen Kalkgehaltes nicht aufbereiten ließ.

beeinflußt, daß eine etwas zu grobe Körnung hervorgerufen wurde.

(T-S)-Wert = austauschbare H-Ionen am Sorptionskomplex

S-Wert = austauschbare Basen am Sorptionskomplex

$\mathrm{T}$-Wert $=$ Sorptionskapazität

$\mathrm{V}$-Wert $=$ Basensättigungsgrad 


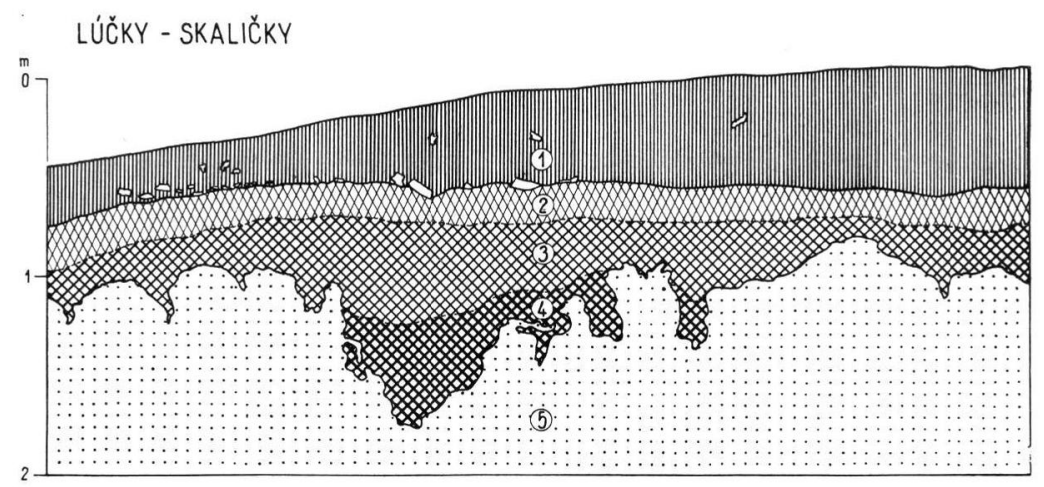

Abb. 4. Lúčky-Skaličky, Terra fusca aus mittelpleistozäner Seekreide. 1 Dunkel graubrauner (2,5 YR 3/2), humoser, mäßig toniger Lehm, prismatisch aufbrechend; vereinzelt durch Korrosion gerundete Bruchstïcke von festem Travertin; an der Basis ein durchgehender Horizont von Schutt paleogener Sandsteine; 2 gräulich gelbbrauner (10 YR 4/5), toniger Lehm, prismatisch aufbrechend; 3 sattbrauner (7,5 YR 3/4), toniger Lehm, scharfkantig blockig; 4 sattbrauner (7,5 YR 4/5), stark toniger Lehm, scharfkantig großblockig, dicht gefügt, Untergrenze taschenförmig, scharf; die Verwitterungsfront besteht aus 2-5 mm großen Kalkkörnern mit weißlichen Verwitterungsrinden, Zwischenräume mit Braunlehmplasma durchsetzt; 5 gelbliche bis weißliche (10 YR 6,5/6), grobkörnige Seekreide mit zahlreichen Wassermollusken (Lymnaea peregra f. ovata [DRAP.]); ziemlich zahlreiche Wurmgänge mit dunkler Wurmlosung und stellenweise dunkelbraune Braunlehmplasma-Einschlämmungen (vgl. Tabelle 1).

Želá tovice be i Přerov (Prerau). Die Verhältnisse stimmen mit denjenigen an der benachbarten Tučiner Fundstelle vollkommen überein (V. LožEK 1961a).

L ú čk y bei Ružomberok (Abb. 4; Tab. 1). Auf der Travertinterrasse Ska li čk y wurde eine mächtige Terra fusca festgestellt, die aus Süßwasserkreide über festen Travertinen entstanden ist (vgl. J. KuKLA \& V. LožEK 1961, Pl. II/2). Sie weist ausgeprägte Verwitterungstaschen auf und ist vom Schutt paläogener Sandsteine überlagert.

Ludrová bei Ružomberok (Abb. 5). Eine sehr mächtige Terra fusca sattbrauner Färbung ist auf festem Travertin des Čerená-Berges ausgebildet, der eine Reliktplatte im Hangenden von Deckenschottern der Niederen Tatra bildet. Die Travertinoberfläche weist sehr deutliche Korrosionserscheinungen auf (V. LožEK 1961c, Pl. V/1),

S v. Ondrej bei Gá novce. Direkt in der Gemeinde tritt ein mächtiger, horizontal gelagerter Komplex von Seekreide mit festen Travertinbänken und Almzwischenlagen auf. In der Oberflächenschicht wurde eine warmzeitliche Molluskenfauna mit Helicigona banatica (Rssm.) festgestellt. Der lockeren, weißen Oberflächenschicht liegt unmittelbar ein Boden mit sehr scharfer Untergrenze auf, dessen Basisschicht einer Terra fusca

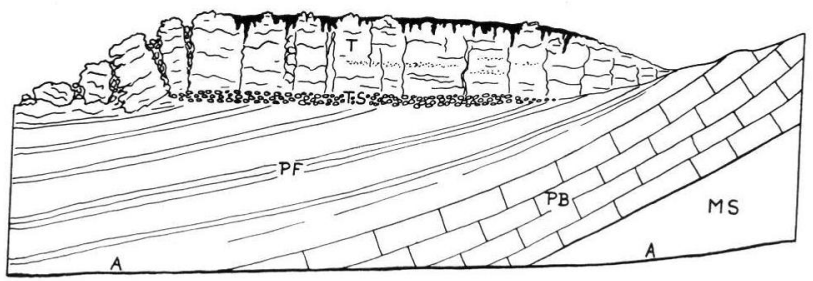

Abb. 5. Čerená bei Ludrová, geologische Position des Travertins mit Terra fusca auf der Oberfläche. T fester Travertin, TS mit Travertin verkittete Terrassenschotter (Deckenschotter - etwa $50 \mathrm{~m}$ über der heutigen Talsohle A), PF zentralkarpatisches Paläogen in Flyschfazies, PB basales Paläogen in Karbonatfazies, MS subtatrisches Mesozoikum; schwarz - Terra fusca aus Travertin (mit zahlreichen tiefen Verwitterungsorgeln). 
ähnelt. Sonst ist das Bodenmaterial mit Detritus paläogener Sandsteine vermengt und enthält wahrscheinlich auch einige äolische Beimischung (V. LožEK 1961b).

Unter den mittelpleistozänen Fundstellen sind auch die Terra fusca-Vorkommen auf der Breccie von Muráň und im Steinbruch von Záskalie bei Púchow zu erwähnen:

Murán (Zentralslowakei). Im Tale Suchý dol am Orte Piecky tritt eine mächtige Breccie auf, die aus Kalkschutt besteht, der durch Sinter verkittet ist. Sie ist stark verkarstet, weist tiefe Erosionseinschnitte auf und enthält eine warmzeitliche Molluskenfauna. Auf der Oberfläche ist eine Terra fusca vorhanden, die meistens nur in Verwitterungstaschen erhalten blieb (V. LožEK 1960, L. SMOLíkovÁ 1961b).

Záskalie bei Púchov im Waagta 1, Westslowakei (Abb. 6). Im verlassenen Steinbruch von Záskalie, in dem Jurakalke der Klippenzone gewonnen wurden, ist das ehemalige Prallufer des Waagflusses aufgeschlossen, das in der Erosionsphase vor der Aufschüttung der Hochterrasse entstanden ist. Der Kalk bildet eine Steilwand über den Sanden der Hochterrasse, der ein Schuttpaket unmittelbar horizontal aufliegt. Die

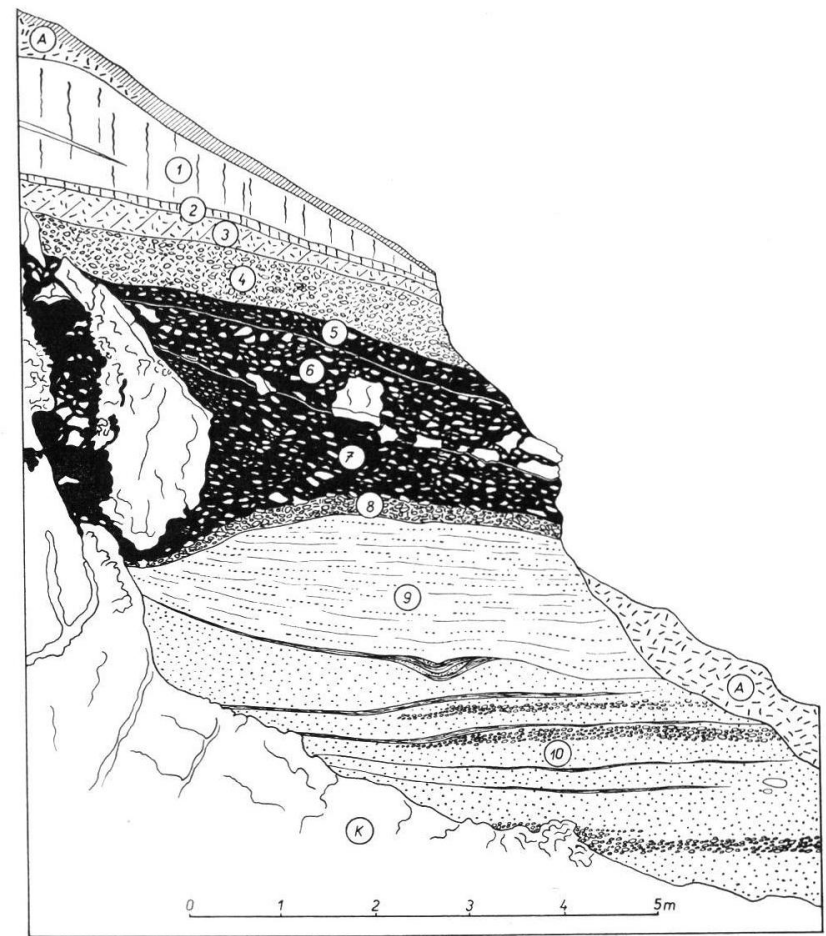

Abb. 6. Záskalie bei Púchov im Waagtal, Deckschichten der Hochterrasse des Waag-Flusses. 1 Hellockerbrauner (10 YR 5/3,5) Löß mit streifenförmigen Kalkausscheidungen, 2 ockerbrauner (10 YR 5/4) Löß mit vereinzelten Kalksteinstücken, 3 Kalkschutt mit graubraunem (10 YR 4,5/2,5) 1ößartigem $\mathrm{Zwischenmittel,} 4$ Kalkschutt mit kalkhaltigem, dunkel graubraunem (10 YR 4/2,5) Lehmzwischenmittel (z. T. Terra fusca-Material), hochinterglaziale Mollusken; 5, 6, 7 korrodierter Kalkschutt mit Terra fusca-Zwischenmittel: 5,6 typisches, dunkel sattbraunes (7,5 YR 4-3,5/3) Terra fusca-Material, Gesteinsstücke stark korrodiert; 7 Zwischenmittel heller (7,5 YR 4,5/4, unreines umgelagertes Terra fusca-Material); dem Schichtpaket 5-7 entspricht die sattbraune (7,5 YR 4/5) Terra fusca-Ausfüllung des Karstschlotes am linken Rand des Profils; 8 Kalkschutt mit unregelmäßig kalkhaltigem, braunem (10 YR 5/3-4), heller geflecktem (10 YR 5/6) Lehmzwischenmittel, hochinterglaziale Mollusken; 9 anlehmige, dunkel gelbbraune (10 YR 4/4-5) Grobsande der WaagHochterrasse, 10 grau- bis gelbbraune Grobsande der Waag-Hochterrasse mit Schluff- und Schotterzwischenlagen; A Aufschüttung, K Jurakalk. 
unterste und die oberen Schichten dieses Pakets sind kalkhaltig und führen eine hochinterglaziale Molluskenfauna mit Helicigona banatica (RSSM.) und Soosia diodonta (FÉr.). Diese Fauna darf mit dem interglazialen Schneckenfund von L. KALAš ("Kočkovská skala") identisch sein. Die mittleren Lagen bestehen aus reinem Terra fusca-Material und stark korrodiertem Kalkschutt. Obwohl ein Teil des Zwischenmittels als Bodensediment zu deuten ist, erfolgte hier auch eine Terra fusca-Bildung an Ort und Stelle, wovon das reine Terra fusca-Material und die Kalkmehlfilme an den Gesteinsstücken zeugen. Außerdem ist der Kalkfelsen mit einem System von Hohlräumen durchsetzt, das eine reine Terra fusca-Ausfüllung aufweist. Diese ist mit den mittleren Schichten des erörterten Schuttpakets direkt verknüpft.

Aus den Lagerungsverhältnissen (vgl. Abb. 6) der warmzeitlichen Schichtenfolge mit Terra fusca ist zu schließen, daß die betreffende Warmzeit unmittelbar der Aufschotterung von Hochterrasse folgen mußte. Nach den Befunden im Ostrauer Gebiet fällt die karpatische Hochterrasse in die Vorrückungsphase der Saale-Vereisung. Demzufolge darf das Terra fusca-Vorkommen von Záskalie als vorletztinterglazial angesprochen werden. Es liegt hier offenbar eine Analogie der mächtigen rubefizierten Bodenkomplexe PK IV vor (vgl. J. KuKLA, V. LožEK \& J. BÁRTA 1962).

Letztinterglaziale Travertine

Hranovnica bei Poprad. Im Tale des Vernár-Baches liegt der Travertinberg $\mathrm{Hinc}$ ava, der aus mehreren Travertinterrassen besteht. Auf der Oberfläche der untersten Terrasse, die eine interglaziale Molluskenfauna und einen paläolithischen Kulturhorizont enthält, ist eine schwach lessivierte Terra fusca ausgebildet. Diese liegt nicht unmittelbar dem frischen Muttergestein, sondern einem Frostschutt über dem festen Travertin auf. Dieses Terra fusca-Vorkommen darf fast sicher als postglazial angesehen werden.

Hradište pod Vrátnom. Diese Fundstelle ist von großer Bedeutung, da hier Travertine von drei verschiedenen Warmzeiten in direkter Superposition auftreten, und zwar von zwei pleistozänen Interglazialen und von Postglazial. Terra fusca ist auf beiden pleistozänen Travertinen ausgebildet (Abb. 7). In beiden Fällen liegt sie der mechanisch verwitterten Oberfläche des Muttergesteins auf. Es liegt hier eine sattbraune, an der Oberfläche schwach lessivierte Terra fusca vor, die auf dem älteren Travertin (Mittel- bis Altpleistozän) bis $1,5 \mathrm{~m}$ tiefe Verwitterungstaschen aufweist und bis $2 \mathrm{~m}$ in das Muttergestein eingreift, während sie in den jüngeren Travertin nur in kurzen, schmal zungenartigen Ausläufern einläuft. Stellenweise ist die Oberfläche des jüngeren Travertins vom Schutt überlagert und Terra fusca ist hier nicht vorhanden. Dort, wo der Kontakt beider pleistozänen Travertine aufgeschlossen ist, liegen die Verhältnisse so, daß der sanft geneigten Oberfläche des älteren Travertins rotbraune, vom Löß überlagerte Terra fusca-Sedimente folgen. Darüber lagert der jüngere pleistozäne Travertin. In Hradiště wurde ein Profil

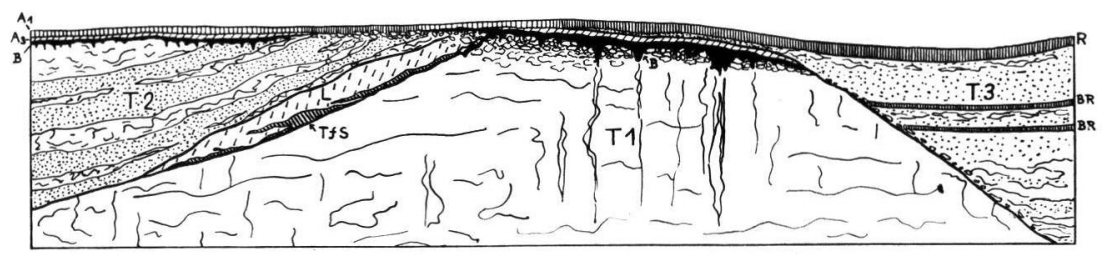

Abb. 7. Hradište pod Vrátnom, Gesamtschema der Travertinserie mit Terra fusca-Bildungen. T 1 Alterer Interglazialtravertin, T 2 jüngerer Interglazialtravertin mit Dauchsandzwischenlagen, T 3 holozäne Travertine und Dauche mit begrabenen Rendsinen (BR), TfS fossile Terra fusca-Sedimente, L lößartiger Lehm, R Rendsina aus holozänem Dauch, $A_{1}, A_{3}, B$ Horizonte der flachgründigen lessivierten Terra fusca aus dem jüngeren Interglazialtravertin, B. B-Horizont der tiefgründigen Terra fusca aus dem älteren Interglazialtravertin. 


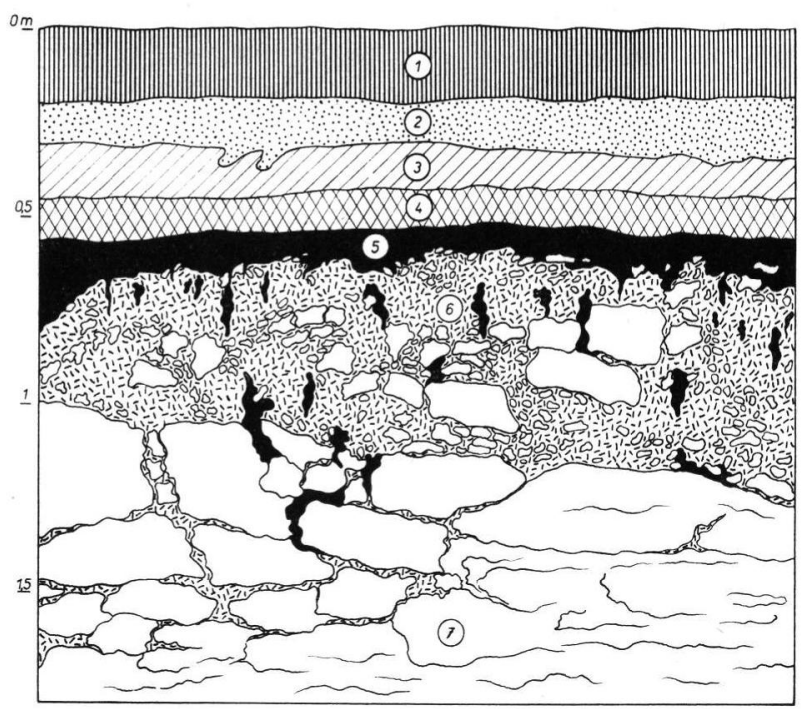

Abb. 8

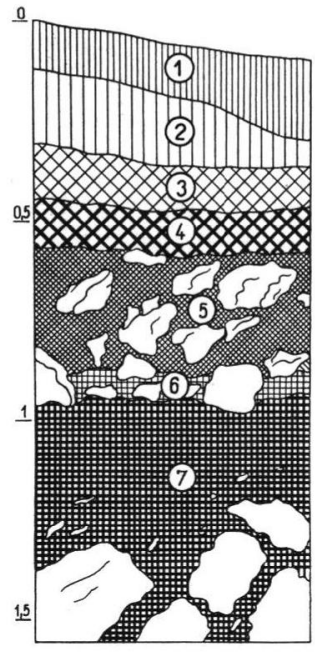

Abb. 9

Abb. 8. Hradište pod Vrátnom, Detailprofil von Terra fusca aus dem älteren Interglazialtravertin. 1 Bräunlich dunkelgrauer, humoser, krümeliger, kalkhaltiger Lehm (Rendsina aus Dauchsand, Ap), 2 weißlicher Dauchsand mit häufigen Humuseinschlämmungen und Wurmgängen $(\mathrm{Ap} / \mathrm{C}), 3$ hell graubrauner Lehm mit zahlreichen Holzkohlen und vereinzelten vorzeitlichen Scherben (Hallstatt$\mathrm{La}$ Tène) (umgelagerter $\mathrm{A}_{3}$-Horizont der lessivierten Terra fusca), 4 gelblich brauner (10 YR 5,5/4), toniger Lehm, unregelmäßig blockig aufbrechend, hellgraue lessivierte Adern, 5 sattbrauner (7,5 YR 4/4), stark toniger Lehm, mittelblockig bis unregelmäßig prismatisch aufbrechend, greift in schmalen Verwitterungsorgeln ins Liegende ein, 6 feinsplitteriger Travertinschutt mit groben Blökken, Zwischenmittel Travertinsand, häufige Braunlehmplasma-Einschlämmungen und tiefe Verwitterungsorgeln; 7 anstehender mittelporiger Travertin, z. T. durch mechanische Verwitterung und Korrosion angegriffen.

Abb. 9. Banka bei Piešt'any, Profil einer Kalkverwitterungslehmserie an der Straße Piešt'anyRadošina unweit des Gasthauses Havran am Westhang des Inovec-Gebirges. 1 Dunkel braungrauer, humoser, staubiger Lehm $\left(A_{1}\right), 2$ hell braungrauer Lehm mit Humuseinschlämmungen $\left(A_{3}\right), 3$ gelbbrauner, toniger Lehm, bröckelig zerfallend, 4 hell rötlichbrauner, toniger Lehm, mittelblockig aufbrechend, 5 satt-rotbrauner, stark toniger Lehm, der das Zwischenmittel einer Dolomitschuttlage bildet, 6 braunroter, stark toniger Lehm an der Unterkante derselben Schuttlage (Gesteinsstücke stark korrodiert), 7 dunkel ziegelroter, stark toniger, jedoch wenig plastischer Lehm, gut krümelnd, zahlreiche kleine weiche orangerote Konkretionen, grobe korrodierte Dolomitstücke und korrodierter anstehender Dolomitfelsen mit tiefen Verwitterungstaschen.

aufgenommen (Abb. 8), in dem über der Terra fusca aus dem älteren Pleistozäntravertin graubraune Lehme mit Scherben aus der Hallstatt-La Tène-Zeit liegen, die wieder von einem jungen (holozänen) Dauch (lockeren Kalktuff) mit Oberflächenrendsina überlagert werden (V. LožfK 1961d). Auf den holozänen Travertinen gibt es keine Spur von Terra fusca-Bildung. Auf der Oberfläche hat sich eine geringmächtige Rendsina entwickelt, abgesehen von mehreren begrabenen Rendsinen innerhalb des Travertinkomplexes. Hradište pod Vrátnom stellt eine sehr bedeutende Fundstelle dar, und man kann erwarten, daß fortschreitende Steingewinnung noch weitere wichtige Profile aufschließen wird. Im Falle, daß sich die Vermutung über das letztinterglaziale Alter des jüngeren Pleistozäntravertins bestätigt, kann seine Terra fusca als postglazial angesprochen werden.

Die Terra fusca-Böden aus Travertin werden durch ihre sattbraune bis rötliche Färbung, die relativ dunkle Tönung, sowie tiefe Verwitterungstaschen und -orgeln gekenn zeichnet. Verglichen mit den Kalksteinen sind die Travertine viel noröser und für Wasser durchlässiger; in höchstem Maße sind diese Eigenschaften bei den lockeren Travertin- 
bildungen (Dauchsand) ausgebildet, die manchmal die Beschaffenheit von groben Seekreiden aufweisen (Lúčky, Sv. Ondrej). Der Travertin wird viel rascher gelöst als kompakte Kalksteine, und die Kolloideinschlämmungen greifen oft sehr tief in das anstehende Gestein ein. Danach kann man vermuten, daß sich die Terra fusca-Bildung aus Travertinen viel rascher vollzieht als aus Kalksteinen.

Mit Ausnahme der Fundstelle Hranovnica und des nicht sicher bestätigten Vorkommens von Hradište pod Vrátnom ist bisher keine Terra fusca aus den letztinterglazialen Travertinen bekannt. Am besten kann diese Erscheinung dort verfolgt werden, wo letztinterglaziale und ältere Travertine in unmittelbarer Nachbarschaft liegen (Bojnice, Lúčky, Umgebung von Gánovce). Daraus kann geschlossen werden, $\mathrm{da} \beta \mathrm{d}$ ie $\mathrm{Ter}$ ra f u s c a in pleistozänen Interglazialen entstand, nicht aber im Postgla zia l, wo nur lokal eine geringe Terra fusca-Bildung stattfand. In älteren Warmzeiten waren die Terra fusca-Bildungsvorgänge viel intensiver als in den jüngeren.

\section{Das gegenseitige Verhältnis von Terra rossa und Terra fusca in den Karstgebieten der Tschechoslowakei}

Beide Terrae calcis-Typen sind in den meisten tschechoslowakischen Karstgebieten vorhanden; allerdings ist der Modus ihrer Erhaltung unterschiedlich und weist einige Gesetzmäßigkeiten auf. Als Oberflächenboden kommt die Terra rossa auf großen Flächen nur im Südslowakischen Karst vor (L. SmoLíková 1959); in anderen Karstgebieten ist sie nur in Korrosionshohlräumen und Verwitterungstaschen, bzw. an beschränkten Flächen in Depressionen erhalten. Hingegen wird die Terra fusca überall dort angetroffen, wo der Kalkstein Ebenen oder flache Abhänge bildet.

An einer ganzen Reihe von Fundstellen, z. B. im Gebirge Považský Inovec, im Südslowakischen und Muráň-Karst, wurde nachgewiesen, daß die Terra rossa im liegenden von Terra fusca auftritt. Sie füllt nur Depressionen und Karsttaschen aus, während die Terra fusca eine mehr oder weniger zusammenhängende Oberflächendecke bildet. Die Terra rossa tritt gewöhnlich als Ausfüllung senkrechter Korrosionshohlräume auf, in welchen an einigen Stellen eine altpleistozäne Fauna festgestellt wurde (vgl. S. 164). Dagegen sind ähnliche Hohlräume (Spalten, Schlote) mit Terra fusca-Ausfüllung eine ziemlich seltene Erscheinung. Daraus kann geschlossen werden, daß in der Zeit, als die Terra rossa in großem Umfang auf der Karstoberfläche auftrat, d. h. im Pliozän und Altpleistozän, zahlreiche vertikale Spalten und Höhlen entstanden, die relativ rasch mit Terra rossaMaterial gefüllt wurden. In späteren Zeiten, als an der durch die pleistozäne kaltzeitliche Abtragung angegriffenen Oberfläche allmählich die Terra fusca die Oberhand gewann, bildeten sich ähnliche Hohlräume nicht mehr und die Verkarstung war von anderer Prägung als in älteren Epochen. Diese Erfahrung wird durch die stratigraphische Erforschung der fossilführenden Höhlenablagerungen vollkommen bestätigt. Während die altpleistozänen und tertiären Ausfüllungen gewöhnlich in senkrechten Hohlräumen erhalten sind, treten ähnliche Lagerungsverhältnisse in der jüngeren Hälfte des Pleistozäns nur ausnahmsweise auf.

\section{Schluß}

Die bisherige Erforschung der Altersfrage von Terrae calcis im tschechoslowakischen Raum brachte folgende Ergebnisse:

1. Die besten Bedingungen für die Bestimmung des geologischen Alters von Terrae calcis bieten die Vorkommen dieser Böden auf $\mathrm{T}$ rave $\mathrm{r}$ t in e $\mathrm{n}$ von verschiedenen Zeitabschnitten des Pliozäns und Quartärs.

2. Das Verhältnis von Terrae calcis zur qua rtären Erosion, ihr Auftreten in den Ausfüllungen der Karsthohlräume und ihr paläopedologi- 


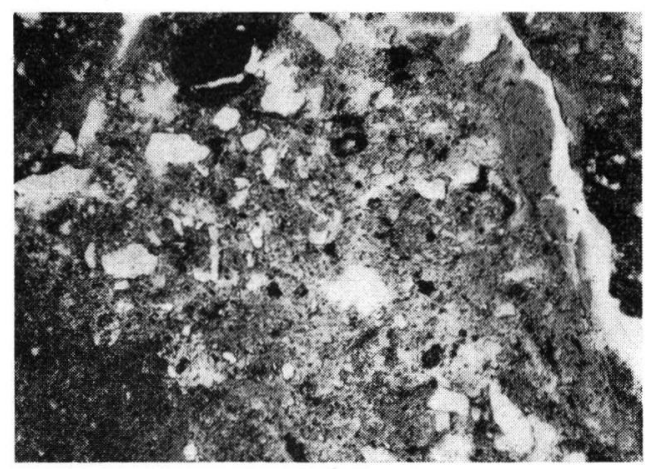

a

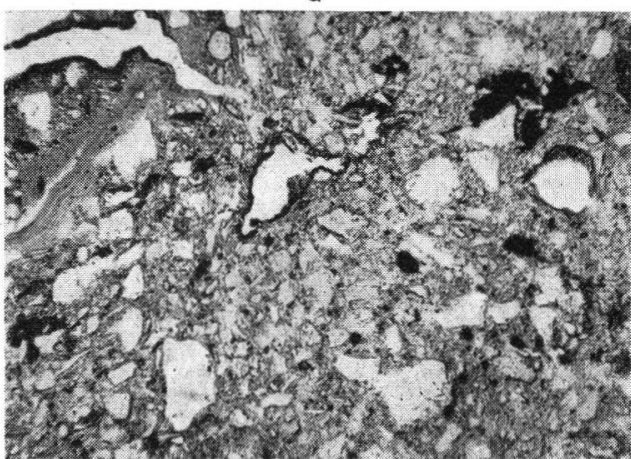

C

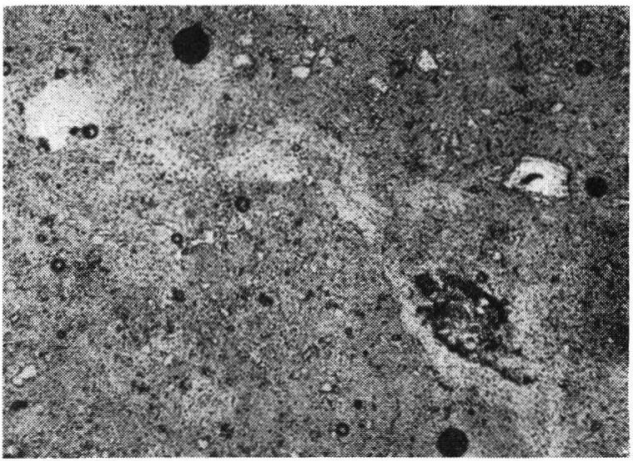

e

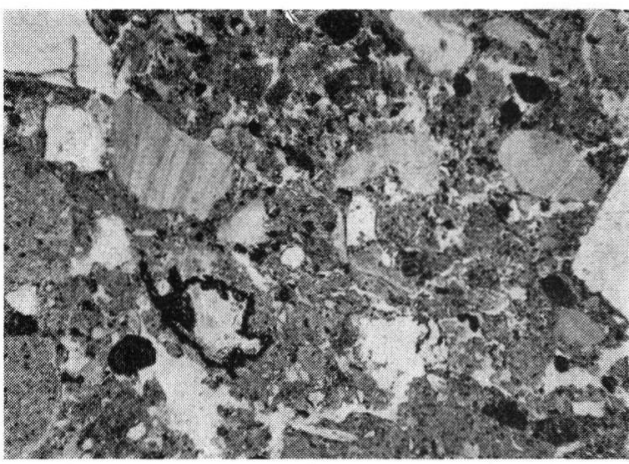

b

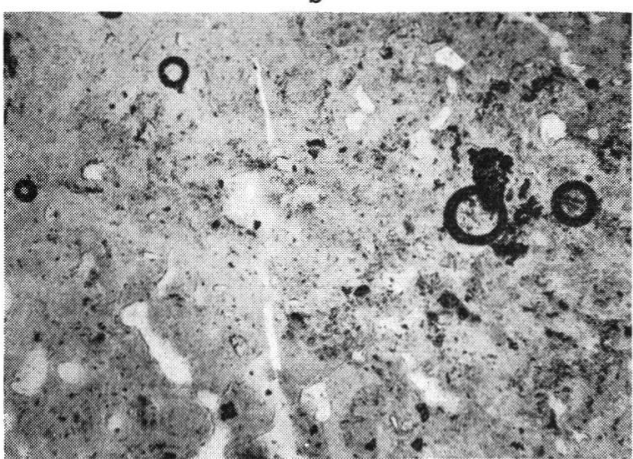

d

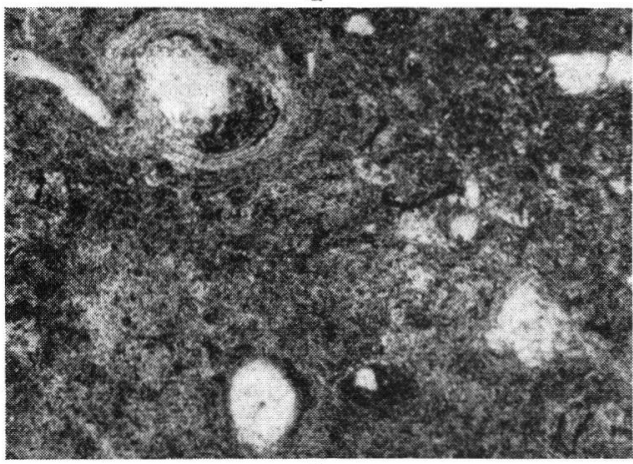

f

Abb. 10. Dünnschliffe von Terrae calcis aus verschiedenaltrigen Travertinen.

a. Zlatý Onyx, allitische Terra rossa aus Pliozäntravertin. Dichte Grundmasse mit zahlreichen Eisenhydroxydausscheidungen und -konkretionen durchsetzt.

b. Dreveník-Ostrá hora, Sediment einer allitischen Terra rossa aus Pliozäntravertin (Höhle am Fuß der Abbauwand). Typisches Brecciengefüge.

c. Tučín, Terra fusca aus mittelpleistozänem Travertin (Probe II/3) Basis des lessivierten $\mathrm{A}_{3}$ Horizontes, schlierige Tonsubstanz nur an Leitbahnen erhalten, sonst ausgewaschen.

d. Tuč́n, B-Horizont derselben Terra fusca (Probe II/4). Dichte bewegliche Grundmasse mit typischem Braunlehmgefüge von leuchtend ockergelber Farbe.

e. Bojnice-Uboče, Terra fusca aus altpleistozänem Travertin (Probe 4). Typischer (B)-Horizont, dichte bewegliche schlierige Grundmasse mit zahlreichen kleinen Eisenhydroxydausscheidungen und größeren Konkretionen.

f. Lúcky-Skaličky, Terra fusca aus mittelpleistozäner Seekreide (Probe 4). B B $_{2}$-Horizont, dichte Grundmasse mit Eisenhydroxydausscheidungen vollständig durchsetzt, die schlierige Tonsubstanz bildet konzentrisch geschichtete Auskleidungen der Leitbahnen.

Foto: BÁrtlová. 


\section{Tabelle 2}

Chronologische Ubersicht der datierbaren Terrae calcis-Vorkommen in der Tschechoslowakei

\begin{tabular}{|c|c|c|}
\hline \multirow{2}{*}{ Fundste $11 \mathrm{e}$} & \multicolumn{2}{|c|}{ Bodenbildung } \\
\hline & Bodentypus & Altersbestimmung \\
\hline $\begin{array}{l}\text { Hranovnica (untere Terrasse) } \\
\text { Hradište pod Vrátnom (jüngerer } \\
\text { Interglazialtravertin) }\end{array}$ & $\begin{array}{l}\text { Flachgründige lessivierte } \\
\text { Terra fusca } \\
\text { Mittelgründige lessivierte } \\
\text { Terra fusca }\end{array}$ & $\begin{array}{l}\text { Holozän } \\
\text { Holozän ? }\end{array}$ \\
\hline $\begin{array}{l}\text { Želátovice bei Prerau } \\
\text { Tučín bei Prerau } \\
\text { Lúčky-Skaličky } \\
\text { Ludrová-Čerená } \\
\text { Sv. Ondrej in der Zips }\end{array}$ & $\begin{array}{l}\text { Mittel- bis tiefgründige } \\
\text { Terra fusca }\end{array}$ & $\begin{array}{l}\text { Letztes (Eem-) oder vor- } \\
\text { letztes (Warmzeit zwischen } \\
\text { Holstein und Eem) Inter- } \\
\text { glazial }\end{array}$ \\
\hline Záskalie bei Púchov & Terra fusca & $\begin{array}{l}\text { Vermutlich vorletztes Inter- } \\
\text { glazial }\end{array}$ \\
\hline $\begin{array}{l}\text { Dudlavá Skala-Höhle } \\
\text { (Südeingang) }\end{array}$ & $\begin{array}{l}\text { Sedimente der siallitischen } \\
\text { Terra rossa }\end{array}$ & $\begin{array}{l}\text { Mittelpleistozän ? } \\
\text { (Holstein bis Eem) }\end{array}$ \\
\hline Muráň (Suchý dol, Piecky) & Terra fusca & Holstein bis Eem \\
\hline $\begin{array}{l}\text { Vyšné Ružbachy-Modzele } \\
\text { Dudince-Gestence } \\
\text { Hradište pod Vrátnom (älterer } \\
\quad \text { Interglazialtravertin) } \\
\text { Bojnice-Úboče } \\
\text { Malé Bielice im Nitra-Tal }\end{array}$ & Meist tiefgründige Terra fusca & $\begin{array}{l}\text { Spätaltpleistozäne Warm- } \\
\text { zeiten bis Eem-Interglazial } \\
\text { (wahrscheinlich in mehreren } \\
\text { Warmzeiten gebildet) }\end{array}$ \\
\hline $\begin{array}{l}\text { Koliňany-Málok } \\
\text { Ivanovce-Skala (jüngere Genera- } \\
\text { tion der Karsttaschen) }\end{array}$ & Terra rossa & $\begin{array}{l}\text { Altpleistozän ? } \\
\text { Altpleistozän }\end{array}$ \\
\hline $\begin{array}{l}\text { Dreveník-Ostrá hora } \\
\text { Levice-Zlatý Onyx } \\
\text { Ratnovce }\end{array}$ & $\begin{array}{l}\text { Allitische Terra rossa } \\
\text { Allitische Terra rossa } \\
\text { Terra rossa }\end{array}$ & $\begin{array}{l}\text { Endpliozän bis } \\
\text { Altestpleistozän }\end{array}$ \\
\hline
\end{tabular}


(Zeitspanne Endpliozän-Quartär)

\begin{tabular}{|c|c|c|}
\hline \multicolumn{2}{|c|}{ A usgangsmaterial } & \multirow{2}{*}{ B e m e rkung } \\
\hline Gesteinsart & Altersbestimmung & \\
\hline $\begin{array}{l}\text { Schutt über Travertin } \\
\text { Travertin }\end{array}$ & $\begin{array}{l}\text { Eem-Warmzeit (Travertin) } \\
\text { bzw. Würm-Eiszeit (Schutt) } \\
\text { Eem-I. bzw. eine der mittel- } \\
\text { pleistozänen Warmzeiten }\end{array}$ & $\begin{array}{l}\text { Flachgründige Terra fusca-Bildun- } \\
\text { gen mit schmalen kleinen Verwit- } \\
\text { terungsorgeln }\end{array}$ \\
\hline $\begin{array}{l}\text { Travertine bzw. Seekreide } \\
\text { (Lúčky) oder Dauch- } \\
\text { sand (Sv. Ondrej) }\end{array}$ & $\begin{array}{l}\text { Mittelpleistozäne Warmzeiten } \\
\text { (Holstein und vorletztes Inter- } \\
\text { glazial) }\end{array}$ & $\begin{array}{l}\text { Gut ausgebildete, meist tiefgrün- } \\
\text { dige Terra fusca mit tiefen Orgeln } \\
\text { und kleinen Verwitterungstaschen }\end{array}$ \\
\hline------- & --------- & --------- \\
\hline $\begin{array}{l}\text { Kalkschutt über } \\
\text { Hochterrasse }\end{array}$ & $\begin{array}{l}\text { Vermutlich vorletztes Interglazial } \\
\text { ev. Eem) }\end{array}$ & $\begin{array}{l}\text { Terra fusca-Bildung aus Jurakalk- } \\
\text { schutt an Ort und Stelle }\end{array}$ \\
\hline-------- & --------- & --------- \\
\hline Ursprünglich Triaskalk & $\begin{array}{l}\text { Oberfläche der Kalksteine durch } \\
\text { intensive pleistozäne Abtragung } \\
\text { angegriffen }\end{array}$ & $\begin{array}{l}\text { Terra rossa-Sediment in einer } \\
\text { warmzeitlichen Höhlenserie }\end{array}$ \\
\hline-------- & $--------\cdots$ & $--------\cdots$ \\
\hline $\begin{array}{l}\text { Kalkbreccie (verkitteter } \\
\text { Schutt) }\end{array}$ & Altpleistozän? (bzw. jünger) & $\begin{array}{l}\text { Nur in Verwitterungstaschen } \\
\text { erhalten }\end{array}$ \\
\hline Travertine & Alt- bis Altestpleistozän & $\begin{array}{l}\text { Typische Terra fusca-Böden in ur- } \\
\text { sprünglicher Lagerung, meist mit } \\
\text { tiefen Verwitterungstaschen und } \\
\text {-orgeln }\end{array}$ \\
\hline-------- & --------- & ---------- \\
\hline Triaskalk & $\begin{array}{l}\text { Oberfläche der Kalke durch plei- } \\
\text { stozäne Abtragung angegriffen }\end{array}$ & $\begin{array}{l}\text { Fossilführende Terra rossa-Sedi- } \\
\text { mente (Málok spätvillafranchisch, } \\
\text { Ivanovce sicher jünger als Villa- } \\
\text { franca) }\end{array}$ \\
\hline------- & ---------- & ---------- \\
\hline Travertine & Pliozän & $\begin{array}{l}\text { Mächtige Terra rossa-Bildungen mit } \\
\text { tiefen Korrosionsorgeln und ge- } \\
\text { räumigen Verwitterungstaschen }\end{array}$ \\
\hline
\end{tabular}


s che r Modus in den Karstgebieten bieten gute ergänzende Kriterien für die Altersbestimmung.

3. Abgesehen von örtlichen, schwach ausgebildeten Terra fusca-Vorkommen, sind alle unsere Terrae calcis als Relikt-bzw. fossile Böden zu werten, die in älteren geologischen Zeiten entstanden sind.

4. Aus den bisherigen Befunden, vor allem aus dem Vergleich von Terrae calcis-Bildungen aus Travertinen verschiedenen Alters, geht hervor, daß die Terra ross a, sowohl die allitische als auch die siallitische Form, zum erstenmal in der Grenzphas e Pliozän-Pleistozän, bzw. in den Warmzeiten des ältesten Plei$s$ to z ä n s gebildet wurde; meist ist sie jedoch älter, nämlich tertiär. Die T e r r a f u sc a ist ein bezeichnendes Produkt der pleistozänen Interglaziale (vgl. Tab. 2).

5. Bisher wurde die Frage nicht vollkommen geklärt, ob die Terra rossa, wenigstens örtlich und in beschränktem Umfang, auch während der Gipfelphasen einiger pleistozäner Interglaziale entstand und inwieweit sich die Terra fusca im Postglazial ausbilden konnte. Einige Befunde deuten auf beschränkte Lokalbildung von Terra fusca i m Holozän.

\section{Schriftenverzeichnis}

Alimen, H.: Colorimétrie de sédiments quaternaires et paléoclimats. Premiers résultats. - Bull. Soc. géol. France (6) 4 (1954), S. 609-619, Paris 1955.

Blanck, E.: Die Mediterran-Roterde (Terra rossa). - Handbuch der Bodenlehre, 3. Bd., S. 194-257, Berlin 1930.

Blanck, E., Oldershausen, E. v. \& Maurmann, G.: Über Roerdebildungen im und auf Zechsteinkalk im mittleren Deutschland. - Chemie der Erde 7, S. 620-640, 1932.

Dvořák, J.: Význam archeologických výkopů v jižní části Moravského krasu pro kvartérní geologii. - Anthropozoikum 6, S. 341-363, Praha 1957.

Fink, J.: Die Böden Osterreichs. - Mitt. geograph. Ges. Wien 100, S. 92-134, Wien 1958.

Franz, H.: Beiträge der Bodenkunde und Bodenbiologie zur Quartärforschung. - Actes IV. Congrès Internat. Quaternaire (Rome-Pise, Août-Septembre 1953), vol. I, S. 250-267, Roma 1956. - - Feldbodenkunde. - 12+583 S., Verl. G. Fromme, Wien-München 1960.

FEJFAr, O.: Die plio-pleistozänen Wirbeltierfaunen von Hajnáčka und Ivanovce/Slowakei/ČSR. I. Die Fundumstände und Stratigraphie. - Neues Jahrbuch für Geologie und Paläontologie, Abh. 111, S. 257-273, Stuttgart 1961 [1961a]. - - Výzkum fosilních obratlovců na ủzemí ČSSR. - Zprávy o geologických výzkumech v roce 1960, S. 170-172, Praha 1961 [1961 b].

Hynie, O.: Geologická stavba širšího okolí lázní Pieštan a jejich thermální zřídla (Structure géologique des environs des bains de Piešt'any et leurs sources thermales). - Sborník státn. geol. Ústavu ČSR 7, S. 619-650, Praha 1927.

Ivan, L': Geologická stavba a minerálne pramene okolia Levíc. - Geologické práce (SAVU) 32, S. 5-22, Bratislava 1952.

KLINGE, H.: Zur Frage der zeitlichen Einordnung rezenter und vorzeitlicher Kalksteinböden der Iberischen Halbinsel. - VIe Congr. internat. Sci. du Sol Paris 1956, Extrait des Rapports présentés au Congrès 5, S. 31-35, Paris 1956. - - Eine Stellungnahme zur Altersfrage von Terra-rossa-Vorkommen (Unter besonderer Berücksichtigung der Iberischen Halbinsel, der Balearischen Inseln und Marokkos). - Z. Pflanzenernährung, Düngung, Bodenkunde 81 (126), S. 56-63, Weinheim 1958.

Kormos, T.: Beiträge zur Kenntnis der Pleistozänfauna des Komitates Nyitra. - Földtani Közlöny 41, S. 802-806, Budapest 1911.

Kretzor, M.: Die altpleistozänen Wirbeltierfaunen des Villányer Gebirges. - Geologica Hungarica, Ser. Palaeont. 27, 264 S., Budapest 1956.

Kubišta, J., Marschalko, R. \& Rozlozsnik, L.: Predbežná zpráva o výskytoch červenice v Juhoslovenskom krase. - Geologický sbornik (SAV) 4, S. 869-873, Bratislava 1953.

Kubiena, W. L.: Bestimmungsbuch und Systematik der Böden Europas. - 392 S., Stuttgart 1953.

KukLA, J.: Survey of Czechoslovak Quaternary: Quaternary Sedimentation Cycle. - Instytut Geologiczny, Prace 34 - Czwartorzed Europy Srodkowej i Wschodniej, Część I, S. 145-154, Warszawa 1961. 
KuKLA, J. \& LožEK, V.: Survey of Czechoslovak Quaternary: Soils. - Ibidem, S. 59-63, Warszawa 1961.

KukLA, J., LožEK, V. \& BÁRTA, J.: Das Lößprofil von Nové Mesto im Waagtal. - Eiszeitalter und Gegenwart 12, S. 73-91, Öhringen 1962.

LožEK, V.: Zoopaleontologický výzkum pleistocénních travertinů. - Zprávy o geologických výzkumech v roce 1957, S. 124-126, Praha 1959. - - Muráňská brekcie (Breccie von Muráñ). - Věstník Ústředního ústavu geologického 35, S. 469-471, Praha 1960. - Stratigrafický výzkum travertinu v Želatovicích u Přerova (Stratigraphische Erforschung des Travertins in Želatovice bei Prerau). - Anthropozoikum 9, S. 47-63, Praha 1961 「1961a]. - - Další interglaciální malakofauny ze Slovenska (Weitere interglaziale Molluskenfaunen aus der Slowakei). - Anthropozoikum 9, S. 77-85, Praha 1961 [1961b]. - Survey of Czechoslovak Quaternary: Travertines. - Instytut Geologiczny, Prace 34 - Czwartorzęd Europy Środkowej i Wschodniej, Część I, S. 81-86, Warszawa 1961 $\lceil 1961 \mathrm{c}\rceil$. - - Biostratigrafický výzkum čs. kvartéru v roce 1960. - Zprávy o geologických výzkumech v roce 1960, S. 173-175, Praha 1961 [1961 d] - - Stratigrafický výzkum jeskyně Dudlavá skala (Stratigraphical Investigation of the Cave "Dudlavá skala"). Československý Kras 13, S. 121-146, Praha 1962.

LožEK, V. \& ProšEK, Fr.: Krasové zjevy v travertinech a jejich stratigrafický význam (Karst Phenomena in Travertines and Their Stratigraphical Importance). - Československý Kras 10, S. 145-158, Praha 1957.

LožEK, V. \& TYráčEK, J.: Stratigrafický výzkum travertinu v Tuč́ně u Přerova (Die stratigraphische Erforschung des Travertines in Tučín bei Prerau). - Anthropozoikum 7, S. 261-296, Praha 1958.

Ložek, V., Sekyra, J., Kukla, J. \& Fejfar, O.: Výzkum Velké Jasovské jeskyně (Die Durchforschung der Großen Jasover Höhle). - Anthropozoikum 6, S. 193-282, Praha 1957.

Marković-Marjanović, J.: Die Bedeutung der fossilen „terra rossa“-Horizonte für die Stratigraphie und Chronologie des Pleistozäns von Jugoslawien. - Verh. geol. Bundesanstalt 1960, S. 8-22, Wien 1960.

MüCKenfausen, Ed.: Bildungsbedingungen und Umlagerung der fossilen Böden der Eifel. - Fortschr. Geol. Rheinlands und Westfalens 2, S. 495-502, Krefeld 1958.

NĚMEJc, Fr.: Výsledky dosavadních výzkumů paleobotanických v kvarteru západního dílu karpatského oblouku. - Rozpravy II. tř́ídy České akademie 53, 35, 47 S., Praha 1944.

PaAs, W.: Rezente und fossile Böden auf niederrheinischen Terrassen und deren Deckschichten. Eiszeitalter und Gegenwart 12, S. 165-230, Ohringen 1962.

Pelíšek, J.: Fosilní terra rossa z jurských vápenců od Brna. - Věstník státn. geol. Ústavu ČSR 13, S. 71-76, Praha 1937.

Petrbok, J.: Ke stáří české rudozemi. - Časopis Národního musea, oddíl přírodovědný 106, S. 152-153, Praha 1932.

Rousek, V. \& VRBA, J.: Inženýrsko-geologické a hydrogeologické poměry širšího okolí lázní Teplic nad Bečvou (Ingenieur- und hydrogeologische Verhältnisse der weiteren Umgebung des Badeortes Teplice nad Bečvou). - Věstník ústředního Ústavu geol. 35, S. 279298, Praha 1960.

Smolíková, L.: Půdní poměry Jihoslovensk ého krasu (Die Bodenverhältnisse des Südslowakischen Karstes). - Acta Universitatis Carolinae, Geologica 3, S. 273-300, Praha 1959. - - Stratigraphical Significance of Terrae calcis Soils. - INQUA VIth Congress, Abstracts of Papers, S. 34-35, Lódz 1961 [1961 a]. - - K výzkumu půd skupiny "terrae calcis" Muráňského krasu (Zur Erforschung der Terrae calcis-Böden im Muráň-Karst, Zentralslowakei). - Věstník Ústředního ústavu geologického 36, S. 373-375, Praha 1961 [1961b].

Werner, J.: Zur Kenntnis der Braunen Karbonatböden ('Terra fusca) auf der Schwäbischen Alb. Arb. geol. paläontol. Inst. Techn. Hochschule Stuttgart, N.F. 16, S. 1-94, Stuttgart 1958.

ŻeBera, K.: Některé zajímavější výsledky výzkum čtvrtohor v oblasti Českého masivu v roce 1951 (Quelques résultats intéressants des recherches faites en 1951 sur les terrains quaternaires dans le domaine du Massif Bohémien). - Anthropozoikum 3, S. 93-124, Praha 1954.

Manuskr. eingeg. 8. 3. 1962.

Anschrift der Verfasser: Dr. Libuše Smolíková, Lehrkanzel der Geologie der Karls-Universität, Prag II, Albertov 6.

Dr. Vojen Ložek, Geologische Zentralanstalt, Prag 1, Malostranské náměstí 19, Tschechoslowakei. 